\title{
TWIK-1 and TREK-1 Are Potassium Channels Contributing Significantly to Astrocyte Passive Conductance in Rat Hippocampal Slices
}

\author{
Min Zhou, ${ }^{1}$ Guangjin Xu, ${ }^{3}$ Minjie Xie, ${ }^{3}$ Xuexin Zhang, ${ }^{2}$ Gary P. Schools, ${ }^{1}$ Liqun Ma, ${ }^{2}$ Harold K. Kimelberg, ${ }^{1}$ and \\ Haijun Chen ${ }^{2}$ \\ ${ }^{1}$ Ordway Research Institute, Albany, New York 12208, ${ }^{2}$ Department of Biological Sciences, University at Albany, State University of New York, Albany, New \\ York 12222, and ${ }^{3}$ Department of Neurology, Tongji Hospital, Tongii Medical College, Huazhong University of Science and Technology, Wuhan 430030, \\ People's Republic of China
}

Expression of a linear current-voltage $(I-V)$ relationship (passive) $\mathrm{K}^{+}$membrane conductance is a hallmark of mature hippocampal astrocytes. However, the molecular identifications of the $\mathrm{K}^{+}$channels underlying this passive conductance remain unknown. We provide the following evidence supporting significant contribution of the two-pore domain $\mathrm{K}^{+}$channel $\left(\mathrm{K}_{2 \mathrm{P}}\right)$ isoforms, TWIK-1 and TREK-1, to this conductance. First, both passive astrocytes and the cloned rat TWIK-1 and TREK-1 channels expressed in CHO cells conduct significant amounts of $\mathrm{Cs}^{+}$currents, but vary in their relative $P_{\mathrm{Cs}} / P_{\mathrm{K}}$ permeability, $0.43,0.10$, and 0.05 , respectively. Second, quinine, which potently inhibited TWIK-1 $\left(\mathrm{IC}_{50}=85 \mu \mathrm{M}\right)$ and TREK-1 $\left(\mathrm{IC}_{50}=41 \mu \mathrm{M}\right)$ currents, also inhibited astrocytic passive conductance by $58 \%$ at a concentration of $200 \mu \mathrm{M}$. Third, a moderate sensitivity of passive conductance to low extracellular $\mathrm{pH}(6.0) \mathrm{supports}$ a combined expression of acid-insensitive TREK-1, and to a lesser extent, acid-sensitive TWIK-1. Fourth, the astrocyte passive conductance showed low sensitivity to extracellular $\mathrm{Ba}^{2+}$, and extracellular $\mathrm{Ba}^{2+}$ blocked TWIK-1 channels at an $\mathrm{IC}_{50}$ of $960 \mu \mathrm{M}$ and had no effect on TREK-1 channels. Finally, an immunocytochemical study showed colocalization of TWIK-1 and TREK-1 proteins with the astrocytic markers GLAST and GFAP in rat hippocampal stratum radiatum. In contrast, another $\mathrm{K}_{2 \mathrm{P}}$ isoform TASK-1 was mainly colocalized with the neuronal marker NeuN in hippocampal pyramidal neurons and was expressed at a much lower level in astrocytes. These results support TWIK-1 and TREK-1 as being the major components of the long-sought $\mathrm{K}^{+}$channels underlying the passive conductance of mature hippocampal astrocytes.

\section{Introduction}

Hippocampal astrocytes showing linear current-voltage $(I-V)$ relationship (passive) $\mathrm{K}^{+}$membrane conductance have been reported by several research groups (Steinhäuser et al., 1992; Bergles and Jahr, 1997; Jabs et al., 1997; D’Ambrosio et al., 1998; Kang et al., 1998; Djukic et al., 2007), and we recently demonstrated that expression of passive $\mathrm{K}^{+}$conductance correlates with functional maturation of hippocampal astrocytes (Zhou et al., 2006). However, the specific $\mathrm{K}^{+}$channels responsible for astrocyte passive conductance are unknown.

The linear $I-V$ relationship suggests predominant expression

Received Dec. 3, 2008; revised May 4, 2009; accepted June 3, 2009.

This work was supported by grants from the National Science Foundation (IOS-0641828 to M.Z.), the American Heart Association (0635125N to H.C.), and Charitable Leadership Foundation, Latham (to M.Z.). G.X. is a recipient of a scholarship from Chinese Scholarship Council (2007101798). We thank Drs. Leonard Kaczmarek (Yale University) and Steve Goldstein (University of Chicago) for kindly providing us rat TWIK-1 in pGEM and rat TREK-1 in pMAX plasmids. We thank Drs. Paul Feustel, Mark Fleck (Albany Medical College), and Kei-Yuan Tseng (Chicago Medical School) for helpful discussion and Zhenhong Zhao for technical assistance.

Correspondence should be addressed to either of the following: Dr. Min Zhou, Ordway Research Institute, 150 New Scotland Avenue, Albany, NY 12208, E-mail: mzhou@ordwayresearch.org; or Dr. Haijun Chen, Department of Biological Sciences, University at Albany, State University of New York, Albany, NY 12222, E-mail: hc323616@albany.edu.

D01:10.1523/JNEUROSCI.5784-08.2009

Copyright $\odot 2009$ Society for Neuroscience $\quad$ 0270-6474/09/298551-14\$15.00/0 of $\mathrm{K}^{+}$conductances that differ from voltage-gated and classic leak $\mathrm{K}^{+}$channels. Expression of the latter would be expected to show Goldman-Hodgkin-Katz (GHK) constant field outward rectification with asymmetric physiological $\mathrm{K}^{+}$gradients (Hille, 2001). Importantly, the passive behavior of astrocyte membrane conductance is not the consequence of interastrocytic coupling. Instead, it most likely reflects the intrinsic properties of functional $\mathrm{K}^{+}$channel expression, because the same passive conductance remained in the excised outside-out patches from passive astrocyte somata (Schools et al., 2006), and in astrocytes of transgenic mice lacking astrocyte-specific gap junction channels (Wallraff et al., 2006).

Several members of the recently discovered two-pore domain $\mathrm{K}^{+}$channel $\left(\mathrm{K}_{2 \mathrm{P}}\right)$ family can exhibit linear $I-V \mathrm{~K}^{+}$conductance with physiological gradients of $\mathrm{K}^{+}$(Kim, 2005; Lotshaw, 2007). Additionally, expression of $m$ RNAs for two $\mathrm{K}_{2 \mathrm{P}}$ isoforms, TWIK$1\left(\mathrm{~K}_{2 \mathrm{P}} 1.1\right)$ and TREK-1 $\left(\mathrm{K}_{2 \mathrm{P}} 2.1\right)$, has recently been reported in a complete transcriptome study of astrocytes isolated from mouse forebrain (Cahoy et al., 2008). When expressed in the heterologous system, the cloned TWIK-1 conducts weakly inward rectifying currents, whereas TREK-1 mediates outwardly rectifying currents (Fink et al., 1996; Lesage et al., 1996).

In this study, we combined studies of cloned rat TWIK-1 and 
TREK-1 channels in heterologous expression system with patchclamp recording and immunocytochemistry from astrocytes in rat hippocampal slices to address the electrophysiological characteristics and the molecular identifications of the $\mathrm{K}^{+}$channels underlying astrocyte passive conductance. Our results show that TWIK-1 and TREK-1 contribute significantly to the astrocyte passive conductance.

\section{Materials and Methods}

\section{Molecular biology}

Rat TWIK-1 cDNA was subcloned into pMAX, a dual-purpose vector for Xenopus oocyte or mammalian cell expression (Rajan et al., 2005). Rat TWIK-1·K274E mutation was created by pfu-based mutagenesis kits (Stratagene) and confirmed by automated DNA sequencing in both directions of the final constructs.

\section{Cell culture and transfections}

Chinese hamster ovary $(\mathrm{CHO})$ cells were maintained in DMEM supplemented with $10 \% \mathrm{FCS}$ in a $5 \% \mathrm{CO}_{2}$ incubator. $\mathrm{CHO}$ cells were seeded in $35 \mathrm{~mm}$ dishes $24 \mathrm{~h}$ before transfection. Cells with at least $80 \%$ confluence were then transfected by Lipofectamine 2000 (Invitrogen) with $3 \mu \mathrm{g}$ of TWIK-1 $\cdot \mathrm{K} 274 \mathrm{E}$ in pMAX, or TREK- 1 in pMAX and $1 \mu \mathrm{g}$ of pEGFP plasmids, and studied $20 \mathrm{~h}$ later. GFP cotransfection was used to identify effectively transfected cells.

\section{Hippocampal slice preparation}

Hippocampal slices were prepared from 4- to 5- week-old Sprague Dawley rats. The procedure was performed in accordance with a protocol approved by the Wadsworth Center, New York State Department of Health Institutional Animal Care and Use Committee. Animals were anesthetized with $100 \% \mathrm{CO}_{2}$, followed by decapitation. The rat brains were removed from the skull and placed in an ice-cold oxygenated $(5 \%$ $\mathrm{CO}_{2} / 95 \% \mathrm{O}_{2}, \mathrm{pH} 7.4$ ) slice preparation solution containing the following (in mM): $26 \mathrm{NaHCO}_{3}, 1.25 \mathrm{NaH}_{2} \mathrm{PO}_{4}, 2.5 \mathrm{KCl}, 10 \mathrm{MgCl}_{2}, 10$ glucose, 0.5 $\mathrm{CaCl}_{2}$, and 240 sucrose. Final osmolarity was $350 \pm 2 \mathrm{mOsm}$. Coronal slices of $300 \mu \mathrm{m}$ thickness were cut with a Vibratome (Pelco 1500) and transferred to a nylon slice holder basket immersed in artificial CSF (aCSF) containing the following (in mM): $125 \mathrm{NaCl}, 25 \mathrm{NaHCO}_{3}, 10$ glucose, $3.5 \mathrm{KCl}, 1.25 \mathrm{NaH}_{2} \mathrm{PO}_{4}, 2.0 \mathrm{CaCl}_{2}$, and $1 \mathrm{MgCl}_{2}$ (osmolarity $295 \pm 5 \mathrm{mOsm})$ at room temperature $\left(20-22^{\circ} \mathrm{C}\right)$. The slices were kept in aCSF with continuous oxygenation $\left(95 \% \mathrm{O}_{2} / 5 \% \mathrm{CO}_{2}\right)$ for at least $60 \mathrm{~min}$ before recording.

\section{Electrophysiology}

Astrocyte recording in slices. Individual hippocampal slices were transferred to the recording chamber, which was constantly perfused with oxygenated aCSF $(2.0 \mathrm{ml} / \mathrm{min})$. Astrocytes located in the CA1 region were identified by infrared-differential interference contrast (IR-DIC) video microscopy (Olympus BX51W1) using a $40 \times$ water-immersion objective and an IR-sensitive CCD camera to display the slice images on a monitor (Zhou et al., 2006). Single- or dual-patch whole-cell currents were amplified by a MultiClamp 700A amplifier, sampled by a Digidata 1322A Interface, and the data acquisition was controlled by PClamp 9.0 software (all from Molecular Devices) installed on a Dell personal computer. The patch pipettes were fabricated from borosilicate capillaries (outer diameter: $1.5 \mathrm{~mm}$, Warner Instrument) using a Flaming/Brown Micropipette Puller (Model P-87, Sutter Instrument). The patch pipettes had the resistance of 3-4 M $\Omega$ when filled with $\mathrm{KCl}$-based pipette solution (see next section in the Materials and Methods). A minimum of 2 $\mathrm{G} \Omega$ seal resistance was required before rupturing the membrane for whole-cell recording. The membrane potential $\left(V_{\mathrm{M}}\right)$ was read in the " $I=$ 0 " mode. We used current-clamp mode for continuing $V_{\mathrm{M}}$ measurements with no holding current applied so that the recording electrode served as a simple potentiometer. Accepted variation of $V_{\mathrm{M}}$ was not more than $\pm 5 \mathrm{mV}$ over a recording lasting for $30 \mathrm{~min}$. All the experiments were conducted at room temperature $\left(20-22^{\circ} \mathrm{C}\right)$.

The membrane capacitance $\left(C_{\mathrm{M}}\right)$, membrane resistance $\left(R_{\mathrm{M}}\right)$, and access resistance $\left(R_{\mathrm{a}}\right)$ were measured using the "Membrane test" protocol in the PClamp 9.0 program. This means that a pair of $\pm 10 \mathrm{mV}$ pulses stepping from the holding potential of $-70 \mathrm{mV}$ was delivered to induce currents near the resting membrane potential. The time constant $(\tau)$ of the step pulse-induced current decay was determined by fitting the current decay with a monoexponential function between the amplitude ranging from $80 \%$ to $20 \%$, and $R_{\mathrm{a}}$ and $C_{\mathrm{M}}$ were solved from $\tau=R_{\mathrm{a}} \times C_{\mathrm{M}}$. The "membrane test" is designed to estimate $\tau$ and the related $R_{\mathrm{a}}$ and $C_{\mathrm{M}}$ values for cells possessing large resting conductances (low $R_{\mathrm{M}}$ ). This is achieved by adding additional charges over the step duration following the exponential decay of step-induced current (see User's Guide for PClamp 9.0 version for details, Molecular Devices). The $R_{\mathrm{M}}$ is calculated by subtracting $R_{\mathrm{a}}$ from the total resistance $\left(R_{\mathrm{M}}=R_{\mathrm{total}}-R_{\mathrm{a}}\right)$, where the $R_{\text {total }}$ is calculated from the end of the test pulse-induced steady-state currents.

Although a $<10 \mathrm{M} \Omega R_{\mathrm{a}}$ could be readily achieved in immature astrocyte recordings in slices, for rats older than 3 weeks the average $R_{\mathrm{a}}$ we could routinely achieve was $14.7 \pm 0.2 \mathrm{M} \Omega(n=19)$, and the average $R_{\mathrm{M}}$ was $2.9 \pm 1.2 \mathrm{M} \Omega(n=19)$. Such a low $R_{\mathrm{M}}$ in series with a large $R_{\mathrm{a}}$ in a whole-cell recording circuit causes a serious voltage-clamping error of $\sim 80 \%$, a product of $V_{\mathrm{C}} \times\left(R_{\mathrm{a}} / R_{\text {total }}\right)$. Therefore, all the voltage values used in passive conductance $I-V$ plots represent the command voltage $V_{\mathrm{C}}$ but not the actual membrane potential $V_{\mathrm{M}}$. In all the biophysical and pharmacological studies of the passive conductance, the recordings were discarded if the $R_{\mathrm{a}}$ varied $>10 \%$ throughout the experiment.

In one series of experiments, dual-patch recording from a single astrocyte was used to directly measure the voltage errors in whole-cell voltageclamp recording (Fig. 1). While the conventional whole-cell voltageclamp recording was performed in one of the electrodes, the command voltage $\left(V_{\mathrm{C}}\right)$-induced actual membrane potential $\left(V_{\mathrm{M}}\right)$ displacement was simultaneously recorded by the second electrode in current-clamp mode without adding holding current (Fig. $1 E$ ).

To study the $\mathrm{K}^{+}$selectivity of the astrocyte passive conductance, 40 $\mathrm{mm}$ and $128.5 \mathrm{~mm} \mathrm{~K}^{+}$aCSF solutions were made by substituting equimolar $\mathrm{NaCl}$ with $\mathrm{KCl}$. For the relative permeability analysis, the modified aCSF solutions containing a concentration of $70 \mathrm{~mm}$ of one the following monovalent cation chloride salts, namely, $\mathrm{K}^{+}, \mathrm{Rb}^{+}, \mathrm{Cs}^{+}$, $\mathrm{Na}^{+}$, or $\mathrm{Li}^{+}$, were made by substituting $3.5 \mathrm{~mm} \mathrm{KCl}$ and $66.5 \mathrm{~mm} \mathrm{NaCl}$ in the solutions. The $\mathrm{pH} 6.0$ bath solution was made by reducing the $\mathrm{NaHCO}_{3}$ concentration to $1.0 \mathrm{~mm}$, which was osmotically compensated for with $\mathrm{NaCl}$. In the passive $\mathrm{K}^{+}$conductance pharmacology experiments the $\mathrm{K}^{+}$channel blockers quinine $(200 \mu \mathrm{M})$ and $\mathrm{Ba}^{2+}(1.2 \mathrm{~mm})$ were dissolved directly in aCSF without compensation for osmolarity.

The standard electrode solution contained the following (in mM): 140 $\mathrm{KCl}, 0.5 \mathrm{Ca}_{2} \mathrm{Cl}, 1.0 \mathrm{MgCl}_{2}$, 5 EGTA, 10 HEPES, $3 \mathrm{Mg}$-ATP, and 0.3 Na-GTP (pH 7.3, $290 \pm 5 \mathrm{mOsm}$ ). The $\mathrm{pH}$ was adjusted to 7.3 with $\mathrm{KOH}$. The $\mathrm{Cs}^{+}$-based electrode solution was made by replacing $\mathrm{KCl}$ with equimolar amount of $\mathrm{CsCl}$.

Electrophysiological recording from transfected $\mathrm{CHO}$ cells. Standard whole-cell patch-clamp recordings were performed with the EPC-10USB amplifier and a Dell 745 computer using PatchMaster software (HEKA Electronik). Patch pipettes with resistances of 2.0-4.0 M $\Omega$ were used. The $R_{\mathrm{a}}$ was compensated for by at least $80 \%$ to minimize voltage errors. Whole-cell currents of $\mathrm{K}_{2 \mathrm{P}}$ channels expressed in CHO cells were recorded with a standard voltage ramp from $-140 \mathrm{mV}$ to $+80 \mathrm{mV}(2.2 \mathrm{~s})$ from a holding potential equivalent to the reversal membrane potential. In untransfected $\mathrm{CHO}$ cells or transfected $\mathrm{CHO}$ cells with EGFP alone, the maximum endogenous whole-cell currents induced by voltage ramp pulses were $<200 \mathrm{pA}(n=15)$. In supplemental Figure 1 (available at www.jneurosci.org as supplemental material), insignificant expression of membrane currents from intact and EGFP-transfected CHO cells are presented. For TWIK-1- or TREK-1-transfected CHO cells, the recordings were discarded if the maximum currents were $<600 \mathrm{pA}$. Currents were low-pass filtered at $5 \mathrm{kHz}$ and sampled at a rate of $1 \mathrm{kHz}$. The pipette solution contained the following (in mM): $140 \mathrm{KCl}, 1 \mathrm{MgCl}_{2}, 10 \mathrm{EGTA}, 1$ $\mathrm{K}_{2}$-ATP, and 5 HEPES. The $\mathrm{pH}$ was adjusted to 7.4 with $\mathrm{KOH}$. For cation selectivity study, the bath solution contained (in $\mathrm{mM}$ ) $135 \mathrm{XCl}, 5 \mathrm{KCl}, 2$ $\mathrm{CaCl}_{2}, 1 \mathrm{MgCl}_{2}$, and 10 HEPES. The $\mathrm{pH}$ was adjusted to 7.4 with $\mathrm{XOH}$ or NMDG. $X$ stands for $\mathrm{Rb}, \mathrm{Cs}, \mathrm{Li}, \mathrm{Na}$, or $\mathrm{K}$. In the $\mathrm{Cs}^{+}{ }^{-}$-based solutions, $\mathrm{Cs}^{+}$is the only conducting cation. Data analysis was performed using Fitmaster (HEKA Elektronik) and IgorPro (WaveMetrics). 
A

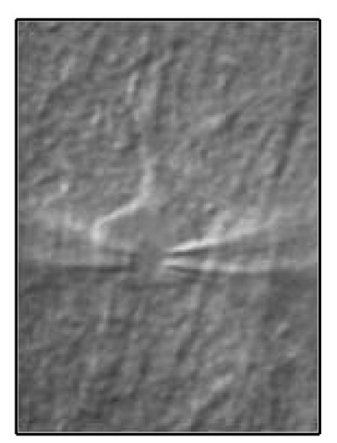

B

\section{Command voltage, $\mathrm{V}_{\mathrm{C}}$}

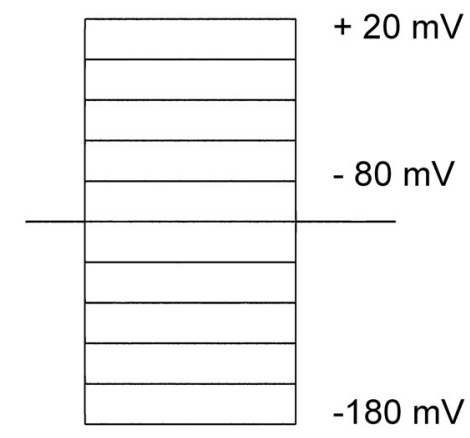

C

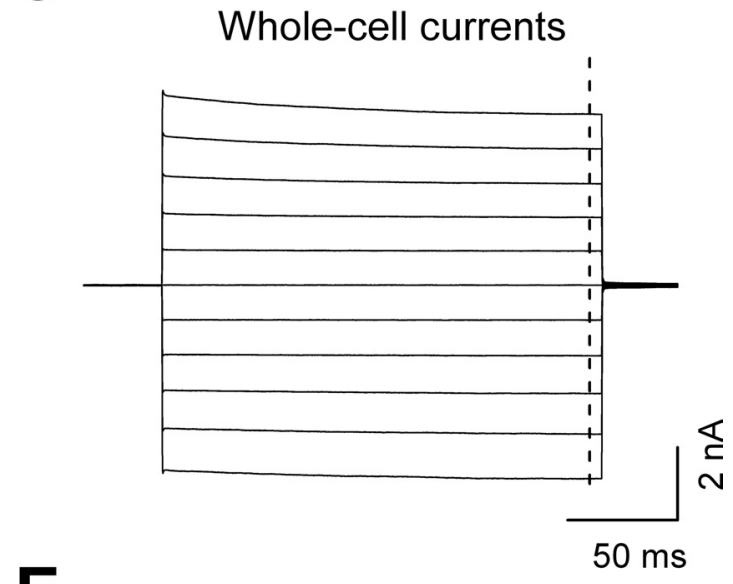

E

\section{Recorded membrane potential, $V_{m}$}

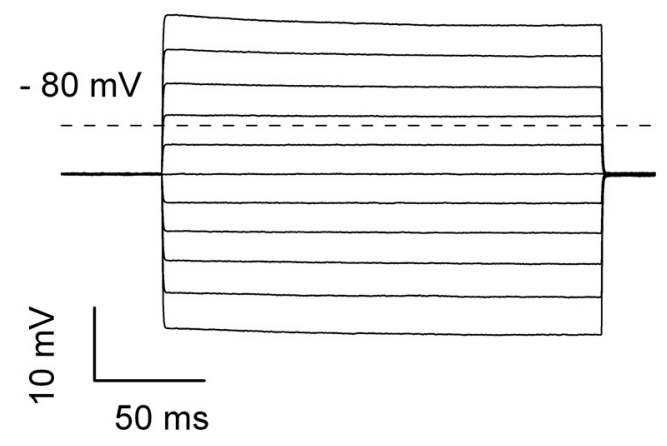

Figure 1. Characteristics of astrocyte passive conductance. $A$, DIC image of an astrocyte in the CA1 stratum radiatum during single-astrocyte dual-patch whole-cell recording, with two recording electrodes (shadows) sealed on the cell somata. While the conventional whole-cell recording was performed in one of the electrodes (the left electrode in $A)$, the actual membrane potential $\left(V_{M}\right)$ change following the delivery of command voltages was recorded by the second electrode simultaneously (right electrode in $\boldsymbol{A}$ ). $\boldsymbol{B}$, Command voltage pulse protocol: 200 ms test voltages were stepped from $-180 \mathrm{mV}$ to $+20 \mathrm{mV}$ with an increment of $20 \mathrm{mV}$ from a holding potential of $-80 \mathrm{mV}$. C, $E$, The whole-cell currents recorded from the left electrode and actual membrane potentials $V_{M}$ recorded from the right electrode, respectively. $\boldsymbol{D}$, Superimposing the current-command voltage relationship $\left(I-V_{C}\right)$ and current-membrane potential relationship $\left(I-V_{\mathrm{M}}\right)$ from the same dual-patch recording revealed an $\sim 80 \%$ deficit of $V_{M}$ from the expected $V_{c}$ in voltage-clamp recording. The outward rectifying $G H K$ currents generated by using the same chemical gradient of $\mathrm{K}^{+}$ in the recording solutions $\left(\left[\mathrm{K}^{+}\right]_{\mathrm{i}} /\left[\mathrm{K}^{+}\right]_{0}=140 / 3.5 \mathrm{mM}\right)$ is also shown in $\boldsymbol{E}$, indicating a considerable deviation of the passive conductance from the expected GHK constant field rectification. As the GHK fit assumed only membrane permeability for the $\mathrm{K}^{+}$ion, the GHK fit yielded a reversal potential of $-93 \mathrm{mV}$, differing from the actual reversal potential of $-87 \mathrm{mV}$ measured from the dual-patch-recorded astrocyte.

\section{Immunohistochemical studies}

The brains were rapidly removed after anesthesia with $\mathrm{CO}_{2}$ and decapitation, and placed in a brain mold on ice. Coronal or sagittal slices $(2 \mathrm{~mm}$ thick) were cut, and the slices were fixed $4 \mathrm{~h}$ in phosphate-buffered $4 \%$ formaldehyde. After cryoprotection in $30 \%$ sucrose/PBS solution, the slices were sectioned at $10 \mu \mathrm{m}$ on a freezing microtome (Microm, from Richard-Allan Scientific). The sections were applied to slides and then treated with $1 \%$ SDS in PBS for 15 min to better expose the epitopes, followed by washing with PBS. Nonspecific binding was blocked with $3 \%$ normal donkey serum in PBS plus $0.01 \% \mathrm{NaN}_{3}$ (NDS/PBS). The antibodies (all from Alomone Labs) for rabbit anti-TWIK-1 (diluted 1:200), rabbit anti-TREK-1 (1:200), and rabbit anti-TASK-1 (1:600) were diluted in PBS containing $1 \% \mathrm{BSA}$ and $0.01 \% \mathrm{NaN}_{3}$. As negative controls, the primary antibodies for $\mathrm{K}_{2 \mathrm{P}}$ channels were blocked with immunizing peptides from the suppliers, incubated $2 \mathrm{~h}$ at room temperature, and then centrifuged $15 \mathrm{~min}$ at 10,000-15,000 rpm. The antibodies and blocked antibodies were incubated with the sections overnight at $4^{\circ} \mathrm{C}$. After washing with PBS, Cy3 donkey anti-rabbit antibody in NDS/PBS (1:1000, Jackson ImmunoResearch Laboratories) was applied and incubated for $1 \mathrm{~h}$ at room temperature. The sections were rewashed and blocked with $2 \%$ normal goat serum/2\% normal donkey serum $/ 0.01 \%$
$\mathrm{NaN}_{3}$ in PBS (NGS/NDS/PBS) for $30 \mathrm{~min}$. Guinea pig anti-GLAST in NGS/NDS/PBS (1:4000, Millipore) was applied for $1 \mathrm{~h}$, and then replaced with anti-GLAST plus monoclonal anti-NeuN Clone A60 (1:200, Millipore). After an overnight incubation at $4^{\circ} \mathrm{C}$, the sections were washed and incubated $1 \mathrm{~h}$ with Alexa Fluor 488 goat anti-guinea pig (1:600, Invitrogen) and Cy5 goat anti-mouse (1:1000, Jackson ImmunoResearch Laboratories) in NGS/NDS/PBS. The sections were washed and mounted in $50 \%$ glycerol $/ 0.01 \% \mathrm{NaN}_{3}$ in PBS.

Images of the sections were acquired on an inverted Carl Zeiss LSM510 META confocal microscope with $25 \times / 0.8 \mathrm{NA}$ and $63 \times / 1.4$ NA objectives. In the laser scanning mode, each fluorochrome was excited and its emission was obtained individually to minimize bleed-through from channel to channel. A DIC image of each $z$-plane was also acquired. Images of the negative control sections were acquired with the same settings used for those with unblocked antibodies. Images were cropped and arranged in Photoshop CS (Adobe Systems). Sections from three animals yielded similar results.

Data analysis

The GHK fits presented in Figure 1 were obtained from the GHK current equation: 
$I=P_{\mathrm{K}} z^{2}\left\{\left(V F^{2}\left[\mathrm{~K}^{+}\right]_{\mathrm{i}}-\left[\mathrm{K}^{+}\right]_{\mathrm{o}} \exp (-z F V / R T)\right) /(1-\exp (-z F V / R T)\}\right.$

where $P_{\mathrm{K}}$ is the permeability of potassium, and $z, V, F, R$, and $T$ have their usual meanings.

The permeabilities of the monovalent cations $\mathrm{Rb}^{+}, \mathrm{Cs}^{+}, \mathrm{Na}^{+}$, and $\mathrm{Li}^{+}$relative to $\mathrm{K}^{+}$were calculated by measuring the shift of equilibrium reversal potentials when $\mathrm{K}^{+}$in the bath solution was replaced by equimolar $\mathrm{Rb}^{+}, \mathrm{Cs}^{+}, \mathrm{Na}^{+}$, and $\mathrm{Li}^{+}$, according to the following equation:

$$
P_{X} / P_{\mathrm{K}}=\exp \left\{\left(E_{X}-E_{\mathrm{K}}\right) /(R T / z F)\right\},
$$

where $P_{\mathrm{K}}$ and $P_{X}$ are the permeability of $\mathrm{K}^{+}$and the test cation, respectively, and $E_{\mathrm{K}}$ and $E_{X}$ are the equilibrium reversal potential of potassium and the test cation, respectively.

Dose-response curves were fitted to the following function:

$$
f_{\mathrm{u}}=\left(1+\left([\text { Blocker }] / \mathrm{IC}_{50}\right)^{h}\right)^{-1},
$$

where [Blocker] is the concentration of the blocker, $\mathrm{IC}_{50}$ is the concentration of the blocker required to achieve $50 \%$ inhibition, $h$ is the Hill coefficient, and $f_{\mathrm{u}}$ is the unblocked fractional current at equilibrium.

All data are presented as means \pm SEM. Two-tailed Student's $t$ tests were used to check for significant differences between two groups of data.

\section{Results}

\section{Characterization of astrocyte passive conductance with} dual-patch-clamp recording

Electrophysiological "passivity" is defined as a linear $I-V$ relationship membrane conductance over a wide range of command voltages in whole-cell voltage-clamp recording. This passive conductance generates a very low membrane resistance $\left(R_{\mathrm{M}}, \sim 3\right.$ $\mathrm{M} \Omega$ ) that causes a voltage error of $\sim 80 \%$ in whole-cell voltageclamp recording (see Materials and Methods). To understand the true nature of passive conductance, it is important to know the actual changes in membrane voltage during whole-cell current recording. This can only be done by dual-patch recording from single astrocytes. Experimentally, two recording electrodes were sealed consecutively to a single astrocytic soma with their tips spaced $<5 \mu \mathrm{m}$ apart (Fig. 1A). One of the electrodes was used to perform conventional whole-cell voltage-clamp recording (Fig. $1 C$ ), and the second to monitor the actual $V_{\mathrm{M}}$ change induced by the $V_{\mathrm{C}}($ Fig. $1 \mathrm{~B}$ ) in the current-clamp mode without adding any holding currents (Fig. $1 E$ ). When the command voltage pulses, ranging from -180 to $+20 \mathrm{mV}$, were applied from a holding potential of $-80 \mathrm{mV}$ (Fig. $1 \mathrm{~B}$ ), the actual $V_{\mathrm{M}}$ displacement amounted to only $20-40 \%$ of the range of the command voltages $V_{\mathrm{C}}\left(\Delta V_{\mathrm{M}} / \Delta V_{\mathrm{C}}=25.8 \pm 4.8 \%, n=4\right.$ paired recordings $)$. Thus, the currents flowing through the $\mathrm{K}^{+}$channels were actually induced by a narrow range of membrane potentials across the membrane from $-108 \mathrm{mV}$ to $-66 \mathrm{mV}$ (Fig. $1 D$, open squares), where most voltage-gated $\mathrm{K}^{+}$channels cannot be activated. Therefore, the passive conductance would be best defined as a resting $\mathrm{K}^{+}$conductance (Hille, 2001).

Had whole-cell access resistance $\left(R_{\mathrm{a}}\right)$ compensation improved voltage-clamping quality, increase in passive conductance or even disclosure of some of the rectifying current components would be possible. Compensating for access resistances by $\sim 80 \%$, however, led neither to a significant passive conductance increase nor disclosure of any rectifying current components $(n=5)$. In dual-patch recording from a single astrocyte, $80 \%$ compensation of access resistances also failed to bring the recorded membrane potentials $\left(V_{\mathrm{M}}\right)$ significantly closer to the command voltages $\left(V_{\mathrm{C}}\right)$. Altogether, the presence of a large rest- ing $\mathrm{K}^{+}$conductance makes access resistances compensation practically impossible in astrocyte whole-cell recording. Thus, no compensation of access resistances was attempted in any of the following studies.

\section{Potassium selectivity of astrocyte passive conductance}

To test the selectivity of the passive conductance for $\mathrm{K}^{+}$over $\mathrm{Na}^{+}$, we changed the bath $\mathrm{K}^{+}$concentration from 3.5 to $40 \mathrm{mM}$ and $128.5 \mathrm{~mm}$ by isotonic replacement for $\mathrm{Na}^{+}$, and measured the change in reversal potential under each experimental condition. Figure $2 A-C$ shows a representative experiment of this kind; the $I-V_{\mathrm{C}}$ relationships were always linear, independent of the bath $\mathrm{K}^{+}$concentrations (Fig. $2 D$ ). Fit of the reversal potentials obtained from the three different extracellular $\mathrm{K}^{+}$concentrations $\left[\mathrm{K}^{+}\right]_{\mathrm{o}}$ gave a shift of $\sim 49.3 \mathrm{mV}$ per 10 -fold increase of $\left[\mathrm{K}^{+}\right]_{\mathrm{o}}$, close to the theoretical value of $\sim 58.2 \mathrm{mV}$ predicted by the Nernst equation (Fig. $2 E$ ). In view of the high $\mathrm{K}^{+}$permeability of the astrocyte membrane, it was possible that the intracellular $\mathrm{K}^{+}$concentration might not remain constant during the substitution of bath solutions with high $\mathrm{K}^{+}$concentrations, and that could at least partially account for the deviation of measured $V_{\mathrm{M}}$ from the relationship predicted by the Nernst equation. Nevertheless, these experiments demonstrated that astrocyte passive conductance is predominantly $\mathrm{K}^{+}$selective.

As the passive conductance always exhibits a linear $I-V$ relationship independent of the $\left[\mathrm{K}^{+}\right]_{\mathrm{o}}$ in the bath solutions, this suggests that either astrocytes predominantly express $\mathrm{K}^{+}$channels with a linear $I-V$ relationship, or a combination of several $\mathrm{K}^{+}$channels with different rectification characteristics. A recent genechip array study identified 2618 astrocyte-enriched genes, including only two isoforms from $\mathrm{K}_{2 \mathrm{P}}$ family, the weakly inward rectifying TWIK-1 and outward rectifying TREK-1, with the TWIK-1 mRNA being threefold higher than the TREK-1 mRNA (Cahoy et al., 2008). Therefore, we have mostly focused on these two $\mathrm{K}^{+}$channels in the following study, and also immunocytochemically studied TASK-1 isoform as a negative control in the sense that its mRNA expression is mainly neuronal (Cahoy et al., 2008).

\section{Conductance and relative $\mathrm{Cs}^{+}$versus $\mathrm{K}^{+}$permeability of astrocytes and cloned TWIK-1 and TREK- $1 \mathrm{~K}^{+}$channels} Most $\mathrm{K}^{+}$channels are negligibly permeable to $\mathrm{Cs}^{+}$, and in fact $\mathrm{Cs}^{+}$blocks many types of $\mathrm{K}^{+}$channels from both sides of the membrane, including the classical voltage-gated $\mathrm{K}^{+}$channels and inward rectifier $\mathrm{K}^{+}$channels (Hille, 2001). However, the $\mathrm{K}_{2 \mathrm{P}}$ isoforms TASK-1 $\left(\mathrm{K}_{2 \mathrm{P}} 3.1\right)$ and TASK-2 $\left(\mathrm{K}_{2 \mathrm{P}} 5.1\right)$ showed a significantly high permeability to $\mathrm{Cs}^{+}$with a $P_{\mathrm{Cs}} / P_{\mathrm{K}}$ value of $\sim 0.2$ (Lopes et al., 2000; Niemeyer et al., 2001). To determine whether the ability to conduct $\mathrm{Cs}^{+}$is shared by other $\mathrm{K}_{2 \mathrm{P}}$ channels, we tested the conductance and relative permeability of $\mathrm{Cs}^{+}$in astrocyte passive conductance in slices, and TWIK-1 and TREK-1 channels heterologously expressed in $\mathrm{CHO}$ cells.

When $\mathrm{K}^{+}$ions were replaced by $\mathrm{Cs}^{+}$in the recording bath and pipette solutions, whole-cell currents could still be recorded in astrocytes in slices (Fig. 3B). The $\mathrm{Cs}^{+}$-conducted currents still showed a linear $I-V$ relationship and a reversal potential of $-81.7 \pm-0.3 \mathrm{mV}(n=5)$, two characteristic properties of $\mathrm{K}^{+}$-conducted astrocyte passive conductance (Fig. 3C). The $\mathrm{Cs}^{+}$-conducted outward $(+20 \mathrm{mV})$ and inward $(-160 \mathrm{mV})$ whole-cell currents in astrocytes actually still amounted to $42 \%$ and $34 \%$ of the $\mathrm{K}^{+}$-conducted whole-cell currents (Fig. $3 C$ ), respectively.

NG2 glial cells belong to a different glial subpopulation in the 
A B
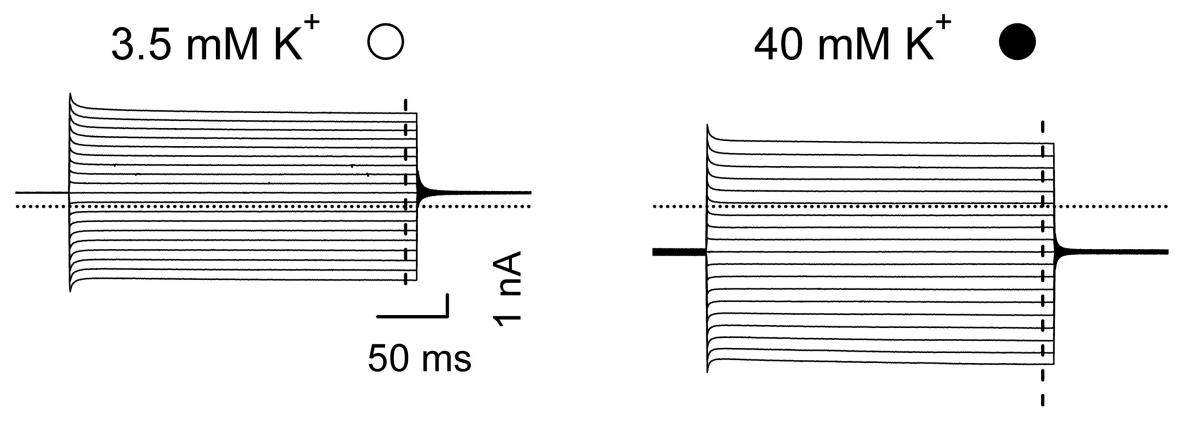

$128.5 \mathrm{mM} \mathrm{K}^{+}$

\section{D}
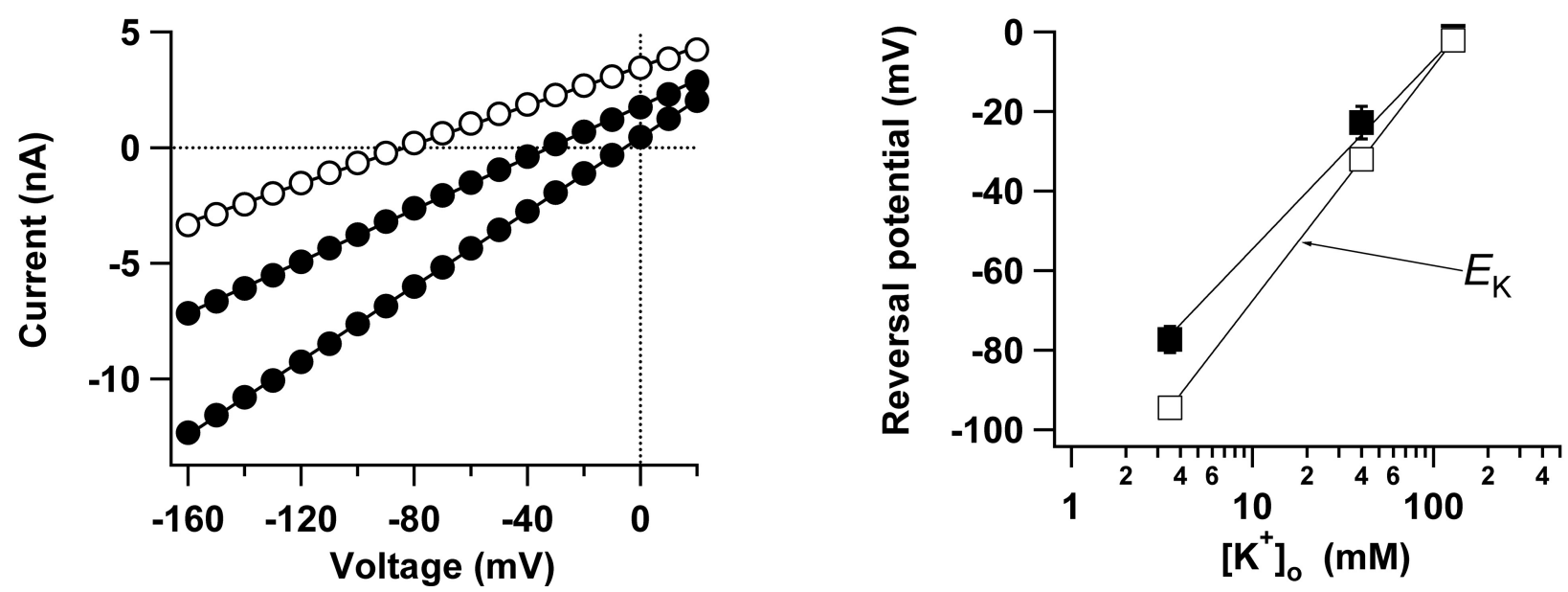

Figure 2. The selectivity of astrocyte passive conductance to $\mathrm{K}^{+} . \boldsymbol{A}-\boldsymbol{C}$, Whole-cell currents evoked by command voltages stepped from $-160 \mathrm{mV}$ to $+20 \mathrm{mV}$ in $10 \mathrm{mV}$ increments in an astrocyte when the bath solution $\mathrm{K}^{+}$concentration was elevated from $3.5 \mathrm{~mm}(\boldsymbol{A})$ to $40 \mathrm{~mm}(\boldsymbol{B})$ and to $128.5 \mathrm{~mm}(\boldsymbol{C})$. $\boldsymbol{D}$, The corresponding current-voltage relationships for the recordings shown in $\boldsymbol{A}-\boldsymbol{C}$ as indicated. Symbols are defined in $\boldsymbol{A}-\boldsymbol{C}$. The currents used for these $I-V$ plots were measured at the ends of the test pulses (dashed vertical lines in $\boldsymbol{A}-\boldsymbol{C}$ ). $\boldsymbol{E}$, The mean reversal potentials in $A-\boldsymbol{C}\left(\right.$ filled squares, $n=4$ ) and the calculated $K^{+}$equilibrium potentials from Nernst equation (open squares, $E_{K}$ ) are plotted against extracellular $K^{+}$concentrations. The continuous lines are linear fits that yielded the slope values of $49.3 \pm 0.8 \mathrm{mV}$ and $58.2 \mathrm{mV}$ for the measured astrocyte $V_{M} s$ and $E_{K} s$, respectively.

CNS that express voltage-gated outward rectifier $\mathrm{K}^{+}$channels as well as a low density of voltage-gated $\mathrm{Na}^{+}$channels (Fig. 3E,F) (Schools et al., 2003; Zhou et al., 2006; Xie et al., 2007). As a negative control, no significant $\mathrm{Cs}^{+}$-conducted whole-cell currents were detected from NG2 glia in slices with the same $\mathrm{Cs}^{+}{ }_{-}$ based solutions (Fig. 3E), indicating effective inhibition of voltage-gated $\mathrm{K}^{+}$channels by $\mathrm{Cs}^{+}$in NG2 glia. Meanwhile, we were still able to record small voltage-gated $\mathrm{Na}^{+}$channels, a characteristic of NG2 glia (Fig. $3 D, E$, inset) $(n=5)$.

The relative permeability of the astrocyte passive conductance to $\mathrm{Cs}^{+}$as well as other monovalent cations, namely, $\mathrm{Li}^{+}, \mathrm{Na}^{+}$, and $\mathrm{Rb}^{+}$, was systematically examined in current-clamp mode. The relative permeability was determined by the relative shift in reversal potentials ( $V_{\mathrm{M}}$ at 0 current) when equimolar amounts of the different monovalent cations were substituted for extracellular $\mathrm{K}^{+}$. Figure $4 A$ shows the shift in the astrocytic reversal potentials in response to the different extracellular ionic substitutions from a recorded astrocyte. The relative permeability of the test cation $\left(P_{X}\right)$ over $\mathrm{K}^{+}\left(P_{\mathrm{K}}\right)$ was calculated according to Equation 2, and is shown in Figure $4 F$ (gray bars). The results showed that the passive conductance of mature astrocytes exhibits a distinctively high $P_{\mathrm{Cs}} / P_{\mathrm{K}}$ ratio of $\pm 0.01(n=3)$.
We next investigated the relative permeability of TWIK-1 and TREK-1 channels to $\mathrm{Cs}^{+}$and other monovalent cations in a heterologous CHO cell expression system. Although the expression of human TWIK-1 channels in Xenopus oocytes produces little measurable currents (Lesage et al., 1996; Goldstein et al., 1998; Kindler et al., 1999; Pountney et al., 1999; Rajan et al., 2005), a recently generated intracellular TWIK-1 mutant (K274E) did produce a significant amount of whole-cell currents (Rajan et al., 2005; Feliciangeli et al., 2007). Taking advantage of this mutant, we used rat TWIK-1 $\cdot \mathrm{K} 274 \mathrm{E}$ in the following ion permeability and pharmacological study.

In voltage-clamp whole-cell recording, the ramp pulseinduced membrane conductance of TWIK-1·K274E channels showed a close to linear $I-V$ relationship in solutions with physiological $\mathrm{K}^{+}$gradients (Fig. $4 \mathrm{~B}$, black line), while TREK-1 channels exhibited outward rectification (Fig. $4 E$, black line). To determine ion selectivity, $135 \mathrm{~mm}$ extracellular $\mathrm{K}^{+}$was sequentially replaced by equimolar amounts of $\mathrm{Cs}^{+}, \mathrm{Na}^{+}, \mathrm{Li}^{+}$, and $\mathrm{Rb}^{+}$, and the change in $I-V$ relationship of membrane conductance and reversal potential were determined by voltage-clamp recording. Representative whole-cell currents of this experiment are shown in Figure $4 B$ for TWIK-1 and Figure $4 E$ for TREK-1, where the 

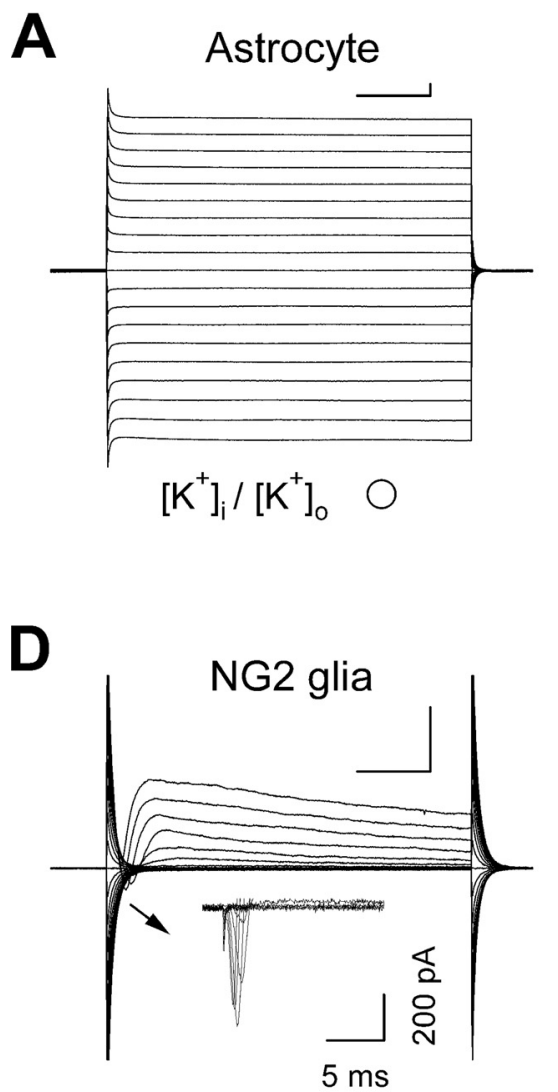

$\left[\mathrm{K}^{+}\right]_{\mathrm{i}} /\left[\mathrm{K}^{+}\right]_{\mathrm{o}}$
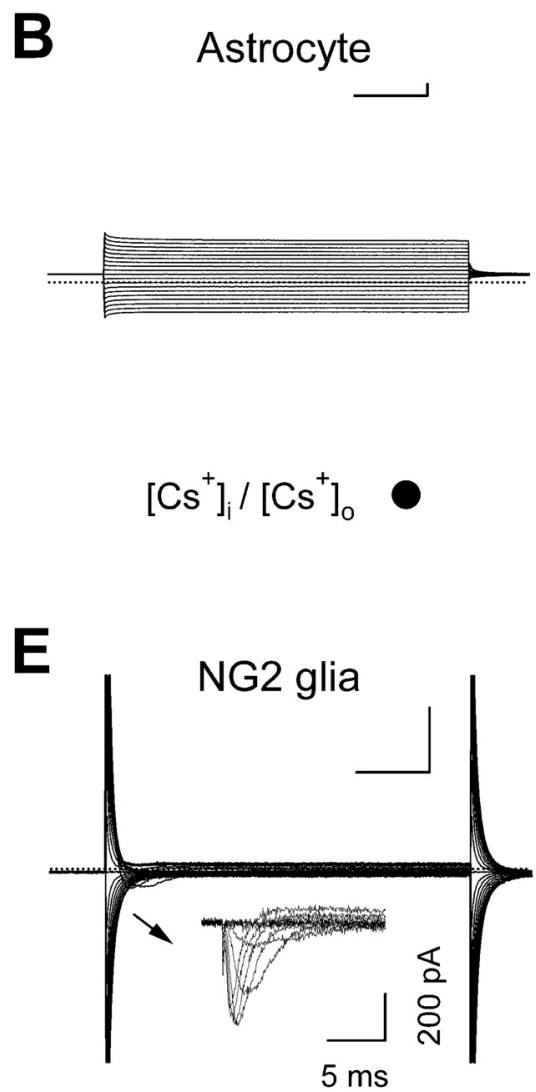

$\left[\mathrm{Cs}^{+}\right]_{\mathrm{i}} /\left[\mathrm{Cs}^{+}\right]_{0}$

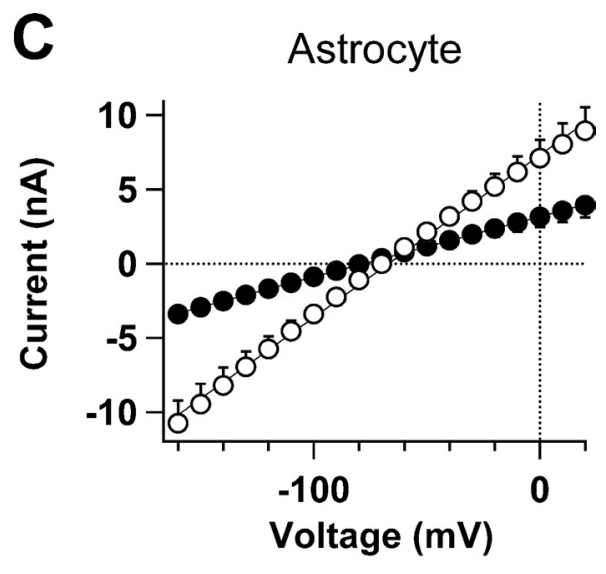

$\mathbf{F}$

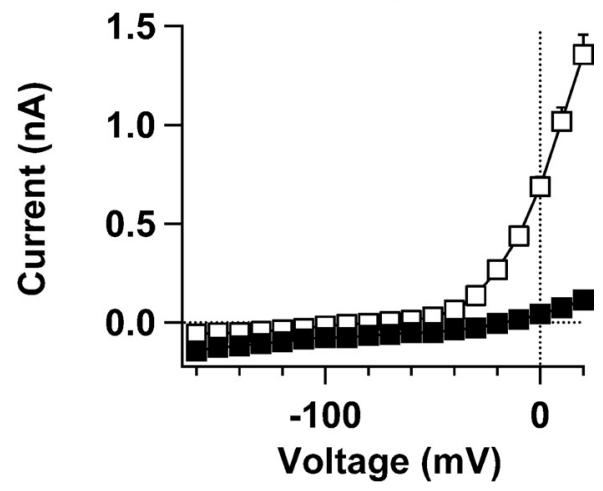

Figure 3. $\mathrm{Cs}^{+}$effects on astrocyte passive conductance. $\boldsymbol{A}, \boldsymbol{B}$, Two representative whole-cell recordings of astrocytes; one recorded with $\mathrm{K}^{+}$-based solutions $(\boldsymbol{A})$ and another with $\mathrm{Cs}^{+}$-based recoding solutions $(\boldsymbol{B})$. $\boldsymbol{C}, \mathrm{I}$-V plots of averaged $\mathrm{Cs}^{+}$-mediated (filled circles, $n=5$ ) and $\mathrm{K}^{+}$-mediated (open circles, $n=5$ ) conductances. When $\mathrm{Cs}{ }^{+}$was substituted for $\mathrm{K}^{+}$in the recording pipette and bath solutions, the $\mathrm{Cs}^{+}$-conducted currents still showed a linear $I-V$ relationship and negative reversal potential in the astrocyte recording $(n=5)$. $\boldsymbol{D}, \boldsymbol{E}$, Two representative NG2 glia whole-cell recordings, one recorded with $\mathrm{K}^{+}$-based $(\boldsymbol{D})$ and the other with $\mathrm{Cs}^{+}$-based $(\boldsymbol{E})$ solutions. Under both conditions, the NG2 glia could still be identified based on low-density expression of voltage-gated $\mathrm{Na}^{+}$channels after capacitive and leak currents subtraction (insets in $\boldsymbol{D}$ and $\boldsymbol{E}$ ) and positive immunostaining to NG2 antibody after recording (data not shown). Calibration: $100 \mathrm{~ms}, 1 \mathrm{nA} . \boldsymbol{F}, \mathrm{I}-V$ plots of $\mathrm{Cs}^{+}$-mediated (filled circles, $n=6$ ) and $\mathrm{K}^{+}$-mediated (open circles, $n=15$ ) conductances of NG2 glia.

currents were first recorded in $135 \mathrm{mM} \mathrm{Na}^{+}$and physiological gradient of $\mathrm{K}^{+}$bath solution (black trace), then in $135 \mathrm{~mm} \mathrm{~K}^{+}$ (dashed black traces) and $135 \mathrm{~mm} \mathrm{Cs}^{+}$(gray traces) bath solutions. The relative permeabilities were calculated from Equation 2 and the data are summarized in Figure $4 D$. TREK-1 channels are moderately permeable to $\mathrm{Cs}^{+}$with a $P_{\mathrm{Cs}} / P_{\mathrm{K}}$ value of 0.10 , which is less than the values reported for the cloned TASK-1 and TASK-2 channels $(\sim 0.2)$ (Lopes et al., 2000; Niemeyer et al., 2001). The mutant TWIK- $1 \cdot \mathrm{K} 274 \mathrm{E}$ channels actually exhibited a lower $\mathrm{Cs}^{+}$permeability ratio of 0.05 . However, independent of the $\mathrm{Cs}^{+}$permeability, $135 \mathrm{~mm} \mathrm{Cs}^{+}$in the bath solution induced significant amounts of inward $\mathrm{Cs}^{+}$currents at the ramp voltage more negative than the reversal potentials in both TWIK$1 \cdot \mathrm{K} 274 \mathrm{E}$ mutant and TREK-1 (Fig. $4 B$, E, gray traces), or both $\mathrm{K}^{+}$ channels are able to conduct inward $\mathrm{Cs}^{+}$currents.

We next substituted physiological gradients of $\mathrm{K}^{+}$with $\mathrm{Cs}^{+}$ in the recording solutions to determine how $\mathrm{Cs}^{+}$conduct membrane currents in the cloned TWIK-1 K274E and TREK- 1 channels under the conditions similar to physiological gradients of $\mathrm{K}^{+}$. TREK-1 channels conducted smaller $\mathrm{Cs}^{+}{ }^{+}$-mediated wholecell currents than that of the $\mathrm{K}^{+}$-mediated currents (at $+50 \mathrm{mV}$, $49.5 \pm 4.8 \mathrm{pA} / \mathrm{pF}$ vs $1118.4 \pm 137.7 \mathrm{pA} / \mathrm{pF}, n=5)($ Fig. $4 F)$, which is comparable to the $P_{\mathrm{Cs}} / P_{\mathrm{K}}$ value of TREK-1 channels described above. Surprisingly, the $\mathrm{Cs}^{+}$-conducted membrane currents of TWIK- $1 \cdot \mathrm{K} 274 \mathrm{E}$ channels were significantly larger than that of the $\mathrm{K}^{+}$conductance (at $+50 \mathrm{mV}, 56.6 \pm 5.9 \mathrm{pA} / \mathrm{pF}$ vs $31.6 \pm 2.5 \mathrm{pA} / \mathrm{pF}, n=6$ ) (Fig. $4 B, C$ ). Also, the $\mathrm{Cs}^{+}$-mediated TWIK-1 conductance showed strong outward rectification in contrast to its linear $\mathrm{K}^{+}$-mediated conductance (Fig. 4B, C).

Together, these results indicate that although the $\mathrm{Cs}^{+}$permeability and the rectification of $\mathrm{Cs}^{+}$conductances of the cloned TWIK-1 mutant and TREK-1 are considerably different from astrocyte passive conductance, both of the cloned $\mathrm{K}^{+}$channels are able to conduct $\mathrm{Cs}^{+}$-mediated inward and outward membrane currents in response to the changing membrane potentials.

\section{Sensitivity of passive conductance and TWIK-1 and TREK-1} channels to quinine, low extracellular $\mathrm{pH}$, and barium We further studied whether the astrocyte passive conductance has pharmacological characteristics similar to that of the TWIK-1 and TREK-1 channels. Although specific blockers for TWIK-1 and TREK-1 channels are not yet available, inhibition of these $\mathrm{K}^{+}$ channels by some commonly used nonspecific $\mathrm{K}^{+}$channel inhibitors, such as quinine, have been reported (Kim, 2005). As shown in Figure 5, $A$ and $B, 100 \mu \mathrm{M}$ quinine significantly inhibited the whole-cell currents of TWIK-1 and TREK-1 channels expressed in CHO cells. TWIK-1 and TREK-1 channels were sensitive to quinine with $\mathrm{IC}_{50}$ values of $\sim 85 \mu \mathrm{M}$ and $\sim 41 \mu \mathrm{M}$, respectively 


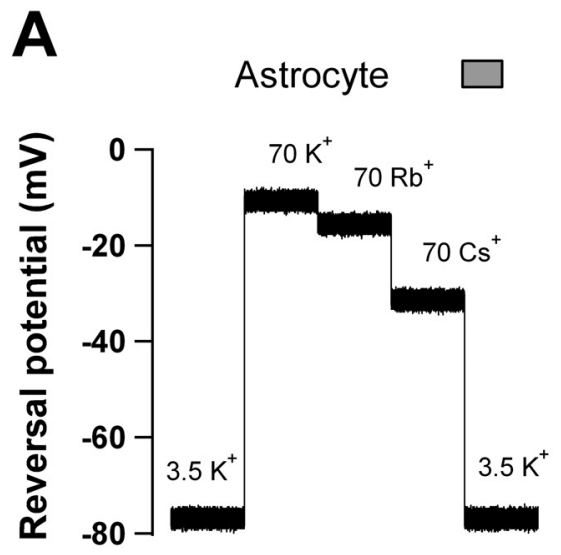

D

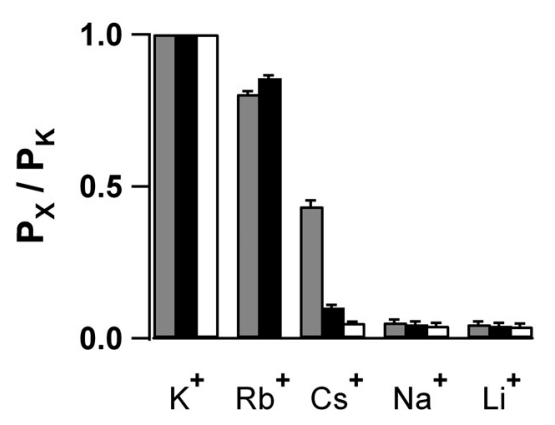

B

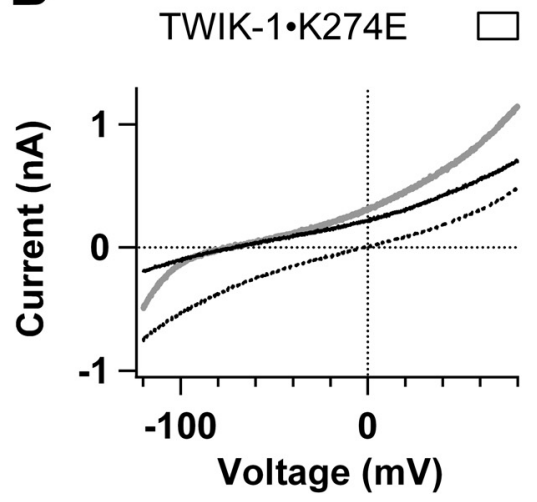

E

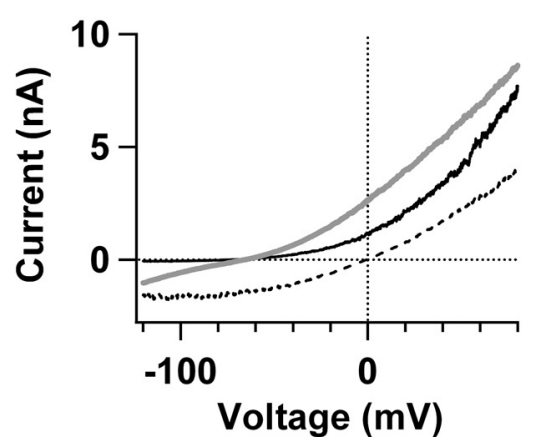

C
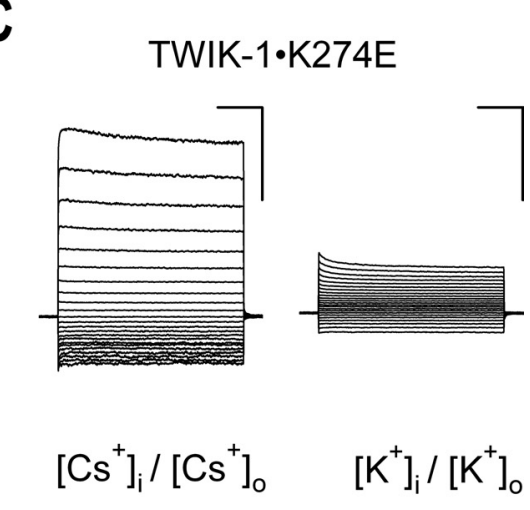

Figure 4. The relative $\mathrm{Cs}^{+}$permeability of astrocyte passive conductance and cloned TWIK- 1 and TREK- $1 \mathrm{~K}^{+}$channels. $\boldsymbol{A}$, Astrocyte reversal potential $V_{\mathrm{M}}$ (at 0 currents) shifted when bath solutions were switched from normal aCSF containing $3.5 \mathrm{~mm} \mathrm{~K}^{+}$to the modified aCSF solutions containing, in sequence, $70 \mathrm{~mm} \mathrm{~K}^{+}$, Rb ${ }^{+}$, and Cs ${ }^{+}$. Astrocyte $V_{M}$ (at 0 current) at the steady-state level was recorded for $2 \mathrm{~s}$ for each ionic condition by continuous current-clamp recording. $\boldsymbol{B}, \boldsymbol{E}$, The voltage ramp-induced whole-cell current traces recorded from two $\mathrm{CH} 0$ cells, one transfected with TWIK-1 (B) and another with TREK-1 (E) $\mathrm{K}^{+}$channels. In each case, the current traces recorded in $135 \mathrm{~mm} \mathrm{Na}^{+}$(black traces), 135 mm K ${ }^{+}$(dashed black traces), and 135 mm $\left(s^{+}\right.$(gray traces) bath solutions are shown. $\boldsymbol{C}, \boldsymbol{F}$, Representative traces of TWIK- 1 and TREK- $1 \mathrm{~K}^{+}$channel whole-cell currents recorded with $\mathrm{Cs}^{+}$- and $\mathrm{K}^{+}$-based solutions as indicated. For the TWIK-1 $\mathrm{K}^{+}$channels, the $\mathrm{Cs}^{+}$-conducted whole-cell currents showed a strong outward rectification and the overall whole-cell current at $+50 \mathrm{mV}$ is significantly larger than that of the $\mathrm{K}^{+}$-conducted whole-cell currents $(56.6 \pm 5.9 \mathrm{pA} / \mathrm{pF}$ vs 31.6 $\pm 2.5 \mathrm{pA} / \mathrm{pF}, n=6)$. The $\mathrm{Cs}^{+}$-conducted TREK- 1 channel currents remained outwardly rectifying and were smaller compared with $\mathrm{K}^{+}$-mediated conductance (at +50 $\mathrm{mV}, 49.5 \pm 4.8 \mathrm{pA} / \mathrm{pF}$ vs $1118.4 \pm 137.7 \mathrm{pA} / \mathrm{pF}, n=5$ ). Calibration: $100 \mathrm{~ms}$ and $1 \mathrm{nA}$. $\boldsymbol{D}$, The relative permeability of astrocyte passive conductance (gray bars), TREK-1 (black bars), and TWIK-1 (open bars) $\mathrm{K}^{+}$channels to different monovalent ions. The relative permeability $\left(P_{X} / P_{K}\right)$ values in each test were calculated from Equation 2.

(Fig. 5C). Consistently, $200 \mu \mathrm{M}$ quinine also inhibited $\mathrm{Cs}^{+}{ }_{-}$ mediated TWIK- 1 and TREK- 1 currents by $72 \pm 8 \%(n=3)$ and $88 \pm 2 \%(n=4)$, respectively (Fig. $5 C$, filled triangle and filled square). For astrocytes in slices, $200 \mu \mathrm{M}$ quinine inhibited $58.0 \%$ of $\mathrm{K}^{+}$-mediated passive currents at a command voltage of +20 $\mathrm{mV}$ [Fig. $5 C$ (filled black circle), $D, E](n=5)$. Quinine $(200 \mu \mathrm{M})$ also inhibited $42.5 \%$ of $\mathrm{Cs}^{+}$-mediated passive currents (Fig. $5 \mathrm{C}$, filled gray circle) $(n=4)$. The inhibition matched well with the overall quinine blockade of TWIK-1 and TREK-1 currents (Fig. $5 C$, open squares and triangles).

In contrast to the TASK- 1 and TASK- $3 \mathrm{~K}_{2 \mathrm{P}}$ isoforms, which are extremely sensitive to extracellular acidic pH (Kim, 2005; Lotshaw, 2007), TWIK-1 channels are moderately sensitive and TREK-1 channels are resistant to low extracellular pH (Fink et al., 1996; Rajan et al., 2005). Changing the $\mathrm{pH}$ in the bath solutions from 7.4 to 6.0 inhibited $\sim 50 \%$ of whole-cell currents of TWIK-1 channels expressed in CHO cells, but had no effect on TREK-1 currents (Fig. 6A, B). For astrocytes recorded from slices, lowering bath solution $\mathrm{pH}$ from 7.4 to 6.0 inhibited $28 \%$ of the wholecell currents at a command voltage of $+20 \mathrm{mV}$ (Fig. $6 C-E)$. Because extracellular low $\mathrm{pH}$ can also inhibit interastrocytic gap junction channels, the gap junction inhibitor, $100 \mu \mathrm{M}$ meclofenamic acid (MFA), was present to avoid recording errors result- ing from varied contribution of transjunctional conductance (Schools et al., 2006; Wallraff et al., 2006). This concentration of MFA by itself had no effect on whole-cell currents. A $<50 \%$ inhibition of astrocyte passive conductance at pH 6.0 is consistent with a combined expression of TWIK-1 and TREK-1 channels. However, it should be noted that because astrocytes also show low level of TASK-1 protein expression by immunocytochemistry (see next Results section), moderate low $\mathrm{pH}$ sensitivity of passive conductance could be alternatively attributable to the TASK-1 expression by astrocytes.

Mammalian $\mathrm{K}_{2 \mathrm{P}}$ channels with four transmembrane segments per subunit are much less sensitive to extracellular $\mathrm{Ba}^{2+}$ than inward rectifier $\mathrm{K}^{+}$channels with two transmembrane segments per subunit (Lotshaw, 2007). As shown in Figure 7A, $800 \mu \mathrm{M}$ extracellular $\mathrm{Ba}^{2+}$ inhibited only $50 \%$ of TWIK-1 $\mathrm{K}^{+}$channel whole-cell currents with an $\mathrm{IC}_{50}$ value of $960 \mu \mathrm{M}$ (Fig. 7C), indicating a low $\mathrm{Ba}^{2+}$ sensitivity. This IC50 value, however, is different from the reported human TWIK-1 channels $\left(\mathrm{IC}_{50}=100 \mu \mathrm{M}\right)$ expressed in Xenopus oocytes (Lesage et al., 1996). The discrepancy could result from either of the following reasons: (1) differences between cloned TWIK-1 channels from human and rats or (2) a potential systematic error because expression of human TWIK-1 channels in Xenopus oocytes produced small whole- 
A

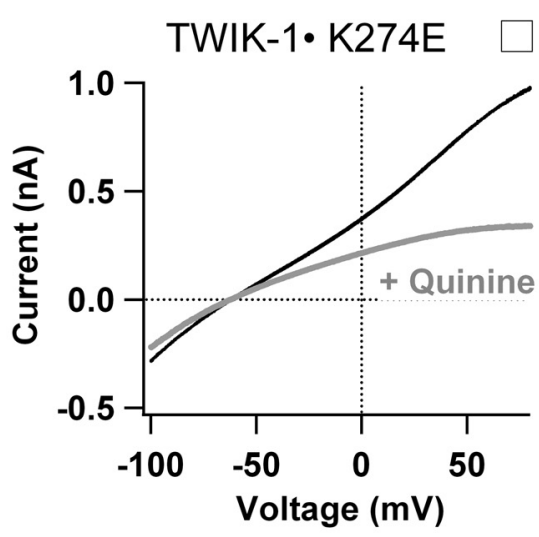

B

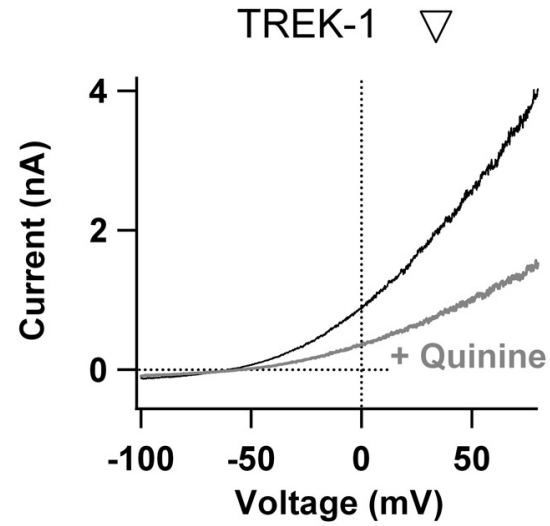

C

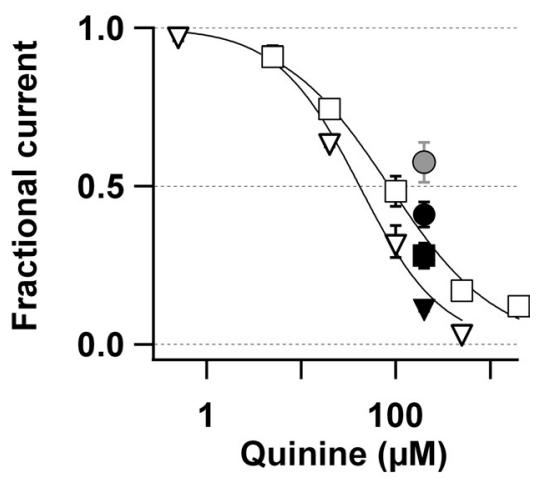

D

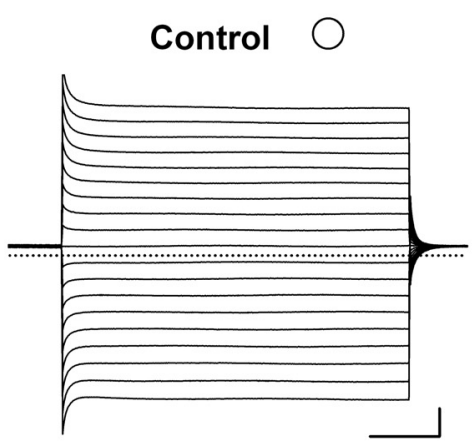

Astrocyte

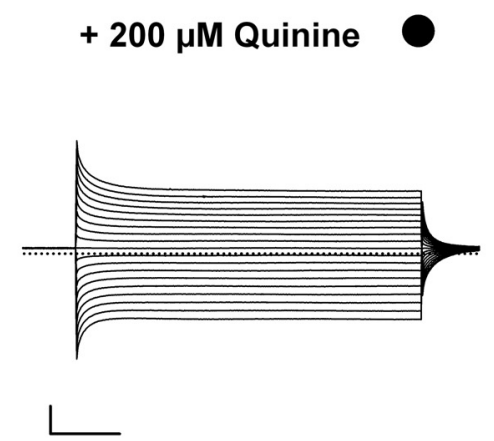

E

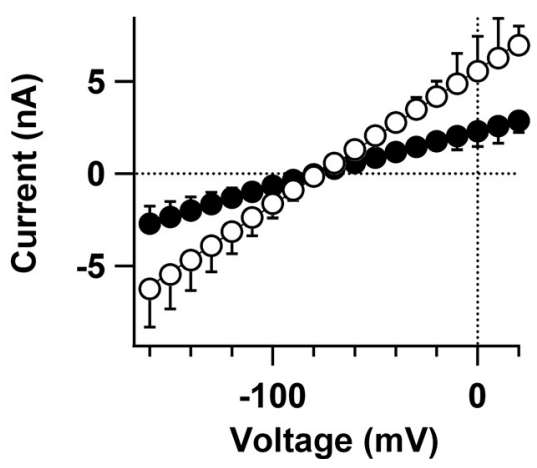

Figure 5. The sensitivity of astrocyte passive conductance and cloned TWIK- 1 and TREK- $1 \mathrm{~K}^{+}$channels to quinine. $\boldsymbol{A}, \boldsymbol{B}$, Representative whole-cell current traces recorded from CHO cells expressing TWIK-1 $(\boldsymbol{A})$ or TREK-1 $(\boldsymbol{B}) \mathrm{K}^{+}$channels induced by voltage ramp pulses before (black traces) and after (gray traces) application of $100 \mu \mathrm{M}$ quinine. After washout of quinine, the traces were the same as control traces. $C$, The dose-response curves of the quinine blockage on TWIK-1 (open triangles) and TREK-1 (filled triangles) channels. The continuous lines were fitted according to Equation 3 that yielded $I_{50}$ values of $41.4 \pm 4.8 \mu \mathrm{m}$ and $85.4 \pm 9.7 \mu \mathrm{m}$ and $h$ values of 0.98 and 0.77 for TREK- 1 and TWIK-1, respectively ( $n=5-6$ for each data point). $D$, Representative astrocyte whole-cell passive currents recorded first in aCSF and then after addition of $200 \mu \mathrm{m}$ quinine. The voltage pulse protocol was the same as in Figure 2 . Calibration: $5 \mathrm{~ms}, 2 \mathrm{nA}$. $\boldsymbol{E}$, The mean current-voltage relationship shows that $200 \mu \mathrm{m}$ quinine (filled circles) inhibited $58 \%$ of passive conductance at the command voltages of $+20 \mathrm{mV}$ and $-160 \mathrm{mV}$ (also presented as filled circle in $\mathbf{C}, n=5)$. Quinine $(200 \mu \mathrm{m})$ similarly inhibited Cs ${ }^{+}$-mediated TWIK-1, TREK-1, and astrocyte passive conductances by $72.0 \%$ (filled square, $n=3$ ), $88.0 \%$ (filled triangle, $n=4$ ), and $42.5 \%$ (gray circle, $n=4)$, respectively $(\boldsymbol{C})$.

oocyte currents not always significantly different from the background (Lesage et al., 1996; Goldstein et al., 1998; Kindler et al., 1999; Pountney et al., 1999; Rajan et al., 2005). Also, $800 \mu \mathrm{M}$ extracellular $\mathrm{Ba}^{2+}$ had no effect on whole-cell currents of TREK-1 channels expressed in $\mathrm{CHO}$ cells (Fig. 6B), which is consistent with the previous reports on mouse and human TREK-1 channels (Fink et al., 1996; Patel et al., 1998, 1999; Meadows et al., 2000).

We next tested the sensitivity of astrocytic passive conductance to $1.2 \mathrm{~mm} \mathrm{Ba}^{2+}$. The whole-cell currents at a command voltage of $+20 \mathrm{mV}$ was inhibited only by $17 \pm 6 \%(n=6)$ (Fig. $7 D, E)$. Such a low sensitivity of astrocyte passive conductance to $\mathrm{Ba}^{2+}$ appeared to be inconsistent with a 3:1 ratio of expression of TWIK-1:TREK-1 channels at the mRNA levels (Cahoy et al., 2008), suggesting that either the functional channels on the membrane might not be proportional to the amount of their mRNAs, or astrocytes express additional $\mathrm{K}_{2 \mathrm{P}}$ isoforms that are insensitive to $\mathrm{Ba}^{2+}$. It should also be noted that the low sensitivity of passive conductance to $\mathrm{Ba}^{2+}$ excludes significant contribution of inward rectifier Kir4.1 $\mathrm{K}^{+}$channels, which are very sensitive to extracellular $\mathrm{Ba}^{2+}\left(\mathrm{IC}_{50}=3.5 \mu \mathrm{M}\right)$ (Ransom and Sontheimer, 1995).
Immunocytochemical staining for TWIK-1, TREK-1, and TASK-1 in hippocampal astrocytes

To determine the expression of TWIK-1 and TREK-1 channel proteins in rat hippocampal astrocytes, we triple immunolabeled rat hippocampal sections with antibodies against the astrocyte marker GLAST, neuronal marker NeuN, or astrocyte marker GFAP, and one each of the three $\mathrm{K}_{2 \mathrm{P}}$ channels TWIK-1, TREK-1, and TASK-1. TASK-1 staining was included because there are controversial reports of TASK-1 expression in astrocytes, as measured by immunocytochemistry (Kindler et al., 2000; Rusznák et al., 2004).

The low-magnification images (Fig. $8 \mathrm{~A}-\mathrm{H}$ ) show the astrocyte markers GLAST and GFAP to be discrete from the neuronal marker NeuN in the CA1 region, with the NeuN antibody mainly labeling the pyramidal cell layer and a few scattered stratum radiatum interneurons. The anti-TASK-1 labeled the pyramidal and interneuron cell bodies (Fig. $8 B-D$ ), and less intensely in $\operatorname{GFAP}(+)$ cell bodies, and only weakly labeled fine structures in the stratum radiatum (Fig. $8 F-H$ ). In contrast, anti-TWIK-1 (Fig. $8 I-L$ ) and anti-TREK-1 (Fig. $8 M-P$ ) did not strongly label neurons and was more intense in a diffuse manner in the stratum 
A

\section{TWIK-1・K274E}

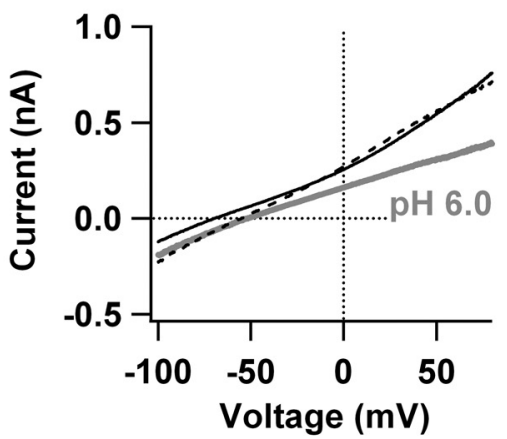

B

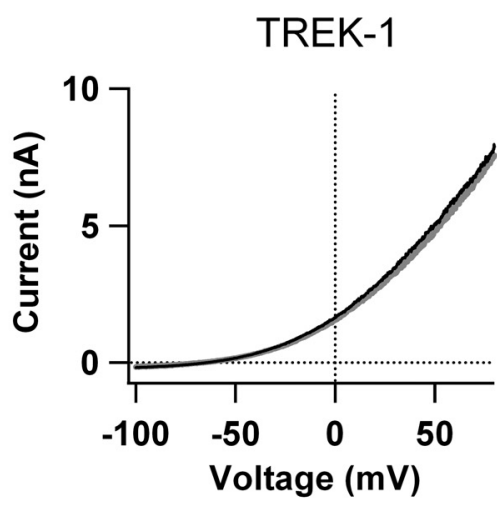

C

D

\section{Astrocyte}
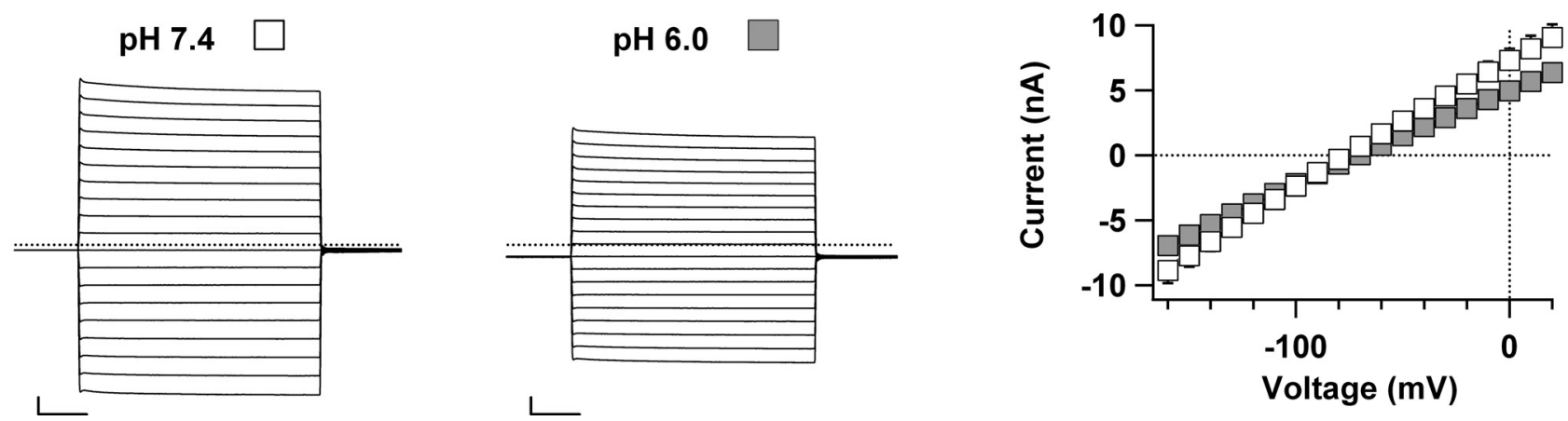

Figure 6. Sensitivity of astrocyte passive conductance and cloned TWIK- 1 and TREK- $1 \mathrm{~K}^{+}$channels to extracellular pH. $A, B$, Representative voltage ramp-induced whole-cell current traces of TWIK-1 and TREK-1 in transfected CHO cells at pH 7.4 (black traces) and pH 6.0 (gray traces). Washout traces are shown as the dashed lines. C, Comparison of effects of extracellular low pH, pH 6.0, on astrocyte passive conductance and expressed TWIK- 1 and TREK- 1 channels. Whole-cell currents at test voltage $+20 \mathrm{mV}$ in the pH 6.0 bath solution (gray bars) are compared with the normalized corresponding values in the $\mathrm{pH} 7.4$ bath solution (open bars) $\left(n=5-7\right.$ for each data point; $\left.{ }^{*} p<0.005\right)$. D. Representative whole-cell current traces recorded from an astrocyte in $\mathrm{pH} 7.4$ and $\mathrm{pH} 6.0$ bath solutions. Calibration: $10 \mathrm{~ms}, 1 \mathrm{nA}$. E, The mean current-voltage relationships for astrocyte recordings obtained in $\mathrm{pH} 7.4$ (open square) and pH 6.0 (gray square) bath solutions ( $n=6$ ). The pooled data show that pH 6.0 significantly inhibited $27 \%$ of the outward passive currents at $+20 \mathrm{mV}$ of test voltage.

radiatum. At this magnification the labeled structures are too small to be resolved. In each case the $\mathrm{K}_{2 \mathrm{P}}$ antibody labeling was blocked by the immunizing peptide (Fig. $8 \mathrm{~B}, J, N$, insets), indicating the specificity of these commercially obtained antibodies.

Higher-magnification images (Fig. 9) show the cell type expression for each $\mathrm{K}_{2 \mathrm{P}}$ isoforms studied. We demonstrated before that a diffuse staining pattern of anti-GLAST in the stratum radiatum reflects expression of this astrocytic-specific glutamate transporter on the abundant astrocyte processes in the neuropil (Schools et al., 2006; Zhou et al., 2006). Therefore, GLAST should be an ideal marker for determining colocalization of a given $\mathrm{K}_{2 \mathrm{P}}$ isoform expression on astrocytic soma and processes. The astrocytes shown in Figure 9 have little or no cytoplasmic labeling of GLAST in the cell body. The surface labeling is assumed to be maintained in the processes. Anti-GFAP was used to further confirm astrocyte labeling. In contrast to GLAST, GFAP immunoreactivity is found in cytoplasmic filaments only in the somata and larger astrocyte processes more proximal to the cell bodies. We found that TWIK-1 and TREK-1 immunoreactivities had a similar diffuse staining pattern as anti-GLAST in the stratum radiatum (Fig. 9J,N), but the staining signals of these two $\mathrm{K}_{2 \mathrm{P}}$ channels were weak in the pyramidal neuron layer (Fig. 8). The $\operatorname{GLAST}(+)$ and $\operatorname{GFAP}(+)$ somata were labeled with anti-TREK- and anti-TWIK-1 (Fig. 9J,N), showing that each of these channels is expressed where these cells were patched for electrophysiological recording. The diffuse TWIK-1 and TREK-1 labeling seen in the neuropil is presumably in astrocyte processes which are too small to be resolved by light microscopy, although some neuronal expression cannot be ruled out. In contrast, TASK-1 and NeuN staining showed a strong colocalization in the pyramidal neuron layer (Fig. 9A-D). This colocalization indicates TASK-1 as a predominant neuronal $\mathrm{K}_{2 \mathrm{P}}$ isoform, that is consistent with a recent transcriptome report showing TASK-1 as a neuron-enriched gene (Cahoy et al., 2008), and the expression of functional TASK-1 currents in hippocampal pyramidal neurons (Taverna et al., 2005) as well as interneurons (Torborg et al., 2006). Figure 9 also shows some astrocytic expression of TASK-1, at least in somata (Fig. $9 E-H$ ).

\section{Discussion}

Astrocyte passive conductance is the resting $\mathrm{K}^{+}$conductance We have recently demonstrated that expression of passive $\mathrm{K}^{+}$ conductance correlates with functional maturation of hippocampal astrocytes (Zhou et al., 2006). By using dual-patch recording in a single astrocyte, we here demonstrate for the first time that the passive conductance is actually induced over a narrow range 


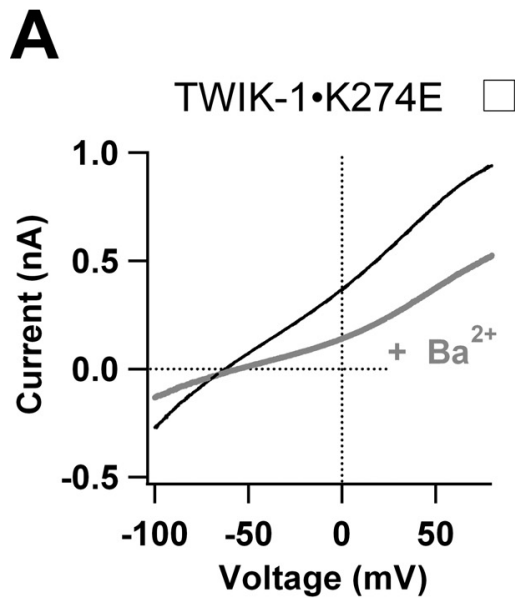

D

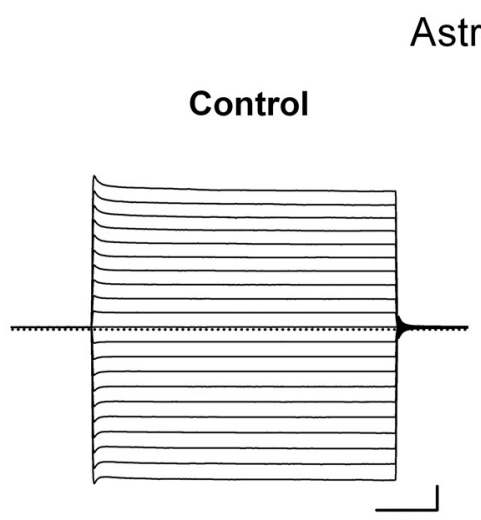

B

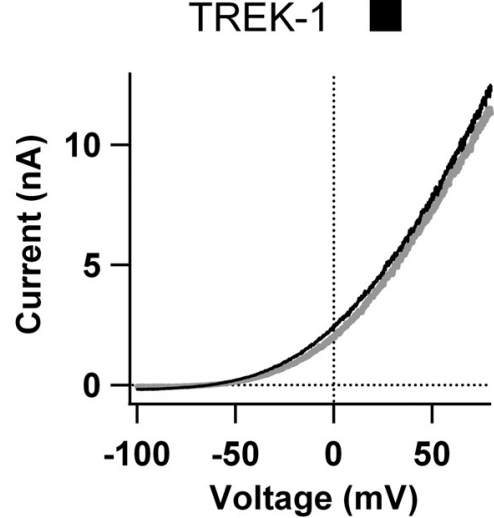

C

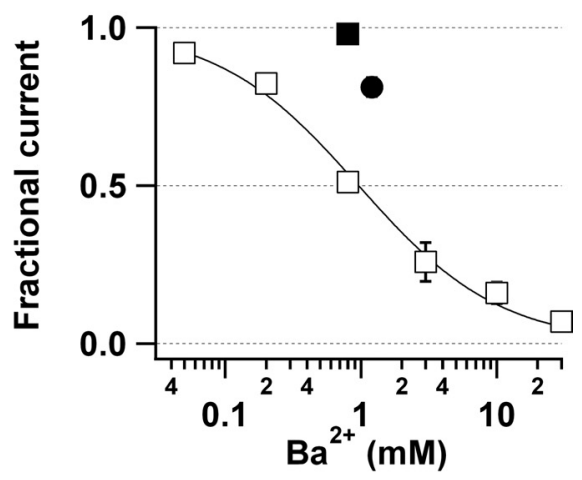

$\mathbf{E}$

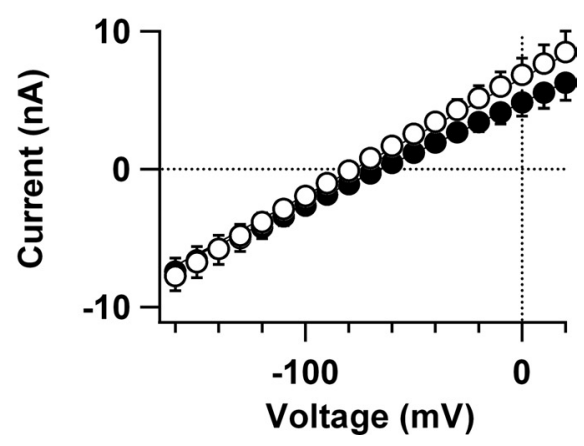

Figure 7. Effects of $\mathrm{Ba}^{2+}$ on astrocyte passive conductance and cloned TWIK-1 and TREK- $1 \mathrm{~K}^{+}$channels. $\boldsymbol{A}, \boldsymbol{B}$, Representative whole-cell current traces recorded from TWIK-1 $(\boldsymbol{A})$ and TREK-1 $(\boldsymbol{B})$. $\mathrm{K}^{+}$channels expressed in $\mathrm{CHO}$ cells induced by voltage ramp pulses before (black lines) and after (gray lines) bath application of $800 \mu \mathrm{m} B \mathrm{a}^{2+}$. The washout recording traces (dashed lines) are superimposable with the control traces. C, Dose-response curves of $\mathrm{Ba}^{2+}$ blockade of TWIK-1 (open squares) $\mathrm{K}^{+}$channels. The continuous line is a fit of Equation 3, yielding an $\mathrm{IC}_{50}$ of $960 \pm 9.8$ $\mu \mathrm{m}$ with $h=0.84$. Blockade of astrocyte passive conductance (filled circle) and TREK-1 (filled square) $\mathrm{K}^{+}$channels at test voltage $20 \mathrm{mV}$ by $1.2 \mathrm{~mm} B \mathrm{a}^{2+}$ and $800 \mu \mathrm{m}$ Ba ${ }^{2+}$, respectively, are also shown ( $n=5-7$ for each data point). $\boldsymbol{D}$, Representative traces of whole-cell currents recorded from an astrocyte before and after application of 1.2 mm Ba ${ }^{2+}$ in bath solution. $\boldsymbol{E}$, The mean current-voltage relationships for the representative recordings shown in $\boldsymbol{D}(n=6)$. Calibration: $10 \mathrm{~ms}$ and $2 \mathrm{nA}$.

of membrane potentials around astrocyte resting membrane potentials, i.e., from $-108 \mathrm{mV}$ to $-66 \mathrm{mV}$. Within this voltage range, activation of voltage-gated outward and voltageindependent inwardly rectifying $\mathrm{K}^{+}$channels should have marginal contribution to the observed passive conductance (Verkhratsky and Steinhäuser, 2000; Zhou and Kimelberg, 2000; Olsen and Sontheimer, 2005; Xie et al., 2007); thus, the passive conductance could be more accurately defined as a resting $\mathrm{K}^{+}$ conductance.

Contribution of TWIK- 1 and TREK- $1 \mathrm{~K}^{+}$conductance to the astrocyte passive conductance

We showed that the proteins for $\mathrm{K}_{2 \mathrm{P}}$ isoforms, TWIK-1 and TREK-1, could be readily detected immunocytochemically in hippocampal astrocytes, which is consistent with the recent transcriptome study indicating the presence of high levels of TWIK-1 and TREK-1 mRNAs in astrocytes (Cahoy et al., 2008). Although colocalization of TASK-1 with GFAP was reported in a prior immunocytochemistry study from rat hippocampal astrocytes (Kindler et al., 2000), we saw the strongest TASK-1 expression in neurons, which corresponds well with the presence of abundant mRNA for TASK-1 in neurons (Cahoy et al., 2008), and expression of functional TASK-1 currents by hippocampal pyramidal neurons and interneu- rons (Taverna et al., 2005; Torborg et al., 2006). The weak colocalization of TASK-1 with GLAST $(+) / \operatorname{GFAP}(+)$ in astrocytes suggests that TASK-1 less likely contributes significantly to the astrocyte passive conductance.

Functionally, the passive conductance exhibits unique biophysical properties that resemble TWIK-1 and TREK-1 channels expressed in $\mathrm{CHO}$ cells: namely, showing the same linear $I-V$ relationship as TWIK-1 and being capable of conducting $\mathrm{Cs}^{+}$currents. The passive conductance also shares a number of pharmacological properties with TWIK-1 and TREK-1 channels, including blockade by quinine, moderate inhibition by low extracellular $\mathrm{pH}$, and especially a low sensitivity to $\mathrm{Ba}^{2+}$. Although single-channel recording would allow further characterization of TWIK-1 and TREK-1 expression in astrocytes, the existence of a high density of passive conductance in the excised patch recording (Schools et al., 2006) suggests this is unlikely to be a feasible approach, so we did not pursue single-channel evidence of TWIK-1 and TREK-1 expression in the present study.

The identification of TWIK-1 and TREK- 1 as $\mathrm{K}^{+}$channels contributing significantly to the astrocytic passive conductance answers two fundamental questions that have long been puzzling. First, at least TWIK-1 gives rise to a linear membrane currents in the physiological recording solutions (Lesage et al., 1997) that 

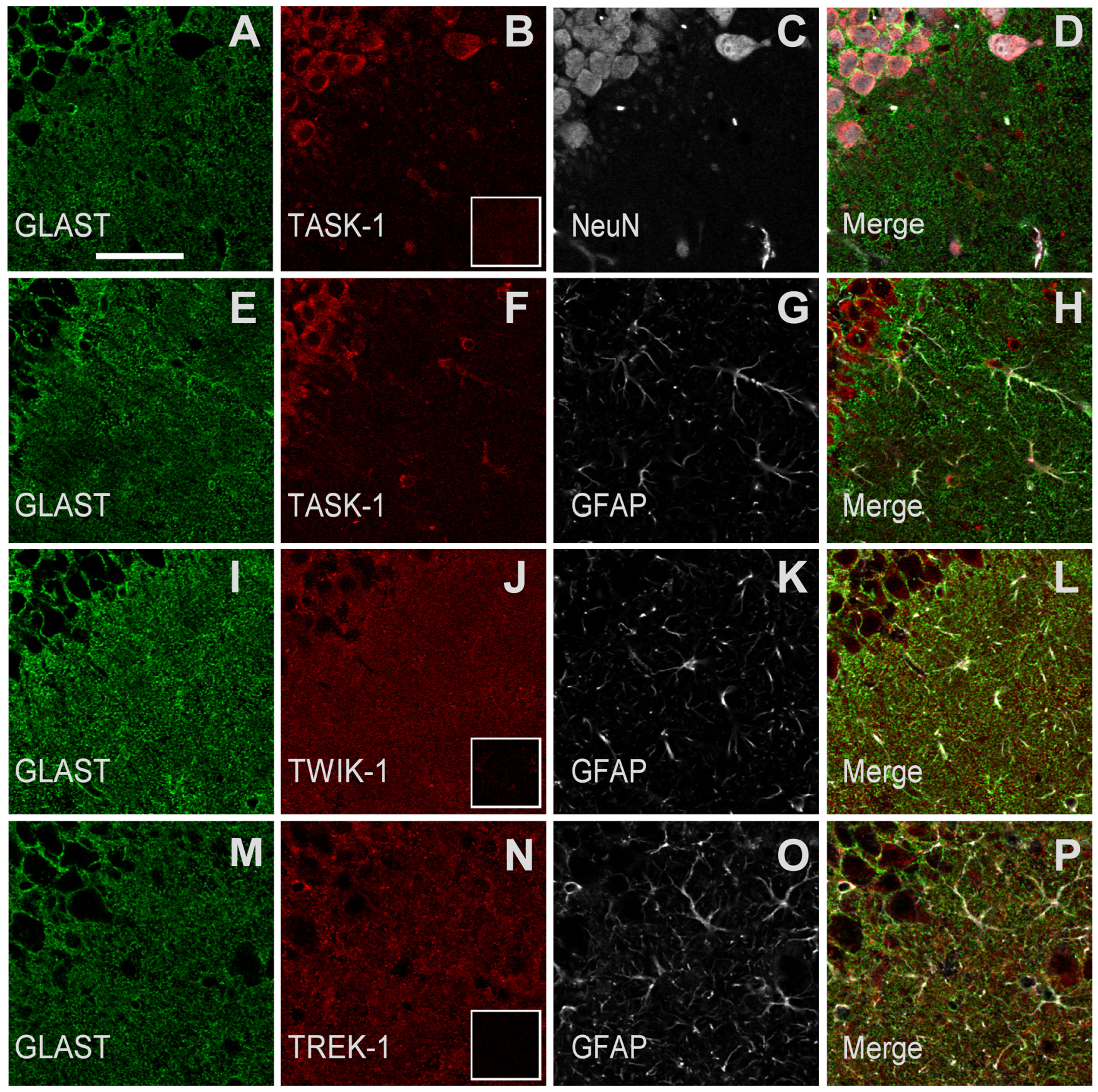

Figure 8. Immunocytochemistry of TASK-1, TWIK-1, and TREK-1 channel proteins in CA1 pyramidal cells and in the stratum radiatum. Coronal hippocampal sections were immunofluorescently labeled for one of the three $K_{2 \mathrm{P}}$ channel proteins, namely, TASK-1 $(\boldsymbol{B}, \boldsymbol{F})$, TWIK-1 (J), and TREK-1 $(\boldsymbol{N})$, GLAST $(\boldsymbol{A}, \boldsymbol{E}, \boldsymbol{I}, \boldsymbol{M})$, and NeuN $(\boldsymbol{C})$ or GFAP $(\boldsymbol{G}, \boldsymbol{K}, \mathbf{0})$ and imaged with confocal microscopy. Each row of images shows the 3 channels and the merged image from a single field in the CA1 pyramidal cell layer (upper left quadrant of each panel) and the stratum radiatum. TASK-1 immunoreactivity was present in NeuN-immunoreactive pyramidal neurons $(\boldsymbol{A}-\boldsymbol{D})$ and to a lesser extent in GFAP- and GLAST-immunoreactive astrocytes $(\boldsymbol{E}-\boldsymbol{H})$. Note that, compared with the TASK- 1 immunoreactivity, anti-TWIK-1 and TREK-1 were more intense in the stratum radiatum neuropil, similar to anti-GLAST. The insets in $\boldsymbol{B}, \boldsymbol{J}$, and $\boldsymbol{N}$ are from images taken from sections treated with the respective $\mathrm{K}_{2 \mathrm{p}}$ antibody preincubated with the blocking peptide. The scale bar in $\boldsymbol{A}$ represents $50 \mu \mathrm{m}$ and applies to all images in this figure.

could partially explain why the passive conductance deviates from the expected outward rectifying GHK currents, a traditionally postulated attribute of leak type $\mathrm{K}^{+}$channels (Hille, 2001). Second, the ability of both TWIK-1 and TREK- 1 channels to conduct $\mathrm{Cs}^{+}$currents explains why the passive conductance of hippocampal astrocytes was only partially blocked by $\mathrm{Cs}^{+}$in slices (D'Ambrosio et al., 1998), and in 70\% of freshly isolated hippocampal astrocytes the inward currents were insensitive to $\mathrm{Cs}^{+}$(Zhou and Kimelberg, 2000).
Involvement of rectifying $\mathrm{K}^{+}$channel currents in astrocytic membrane conductance

Our results show that the inward rectifier potassium channel Kir4.1 does not contribute to the measured passive conductance because (1) in $\mathrm{Cs}^{+}$-based recording solutions, which should completely block Kir4.1 channels, we still observed a significant amount of $\mathrm{Cs}^{+}$-conducted whole-cell currents; (2) the passive conductance remained linear even with elevated extracellular $\mathrm{K}^{+}$ concentrations (Fig. 2), and the presence of Kir4.1 would lead to 


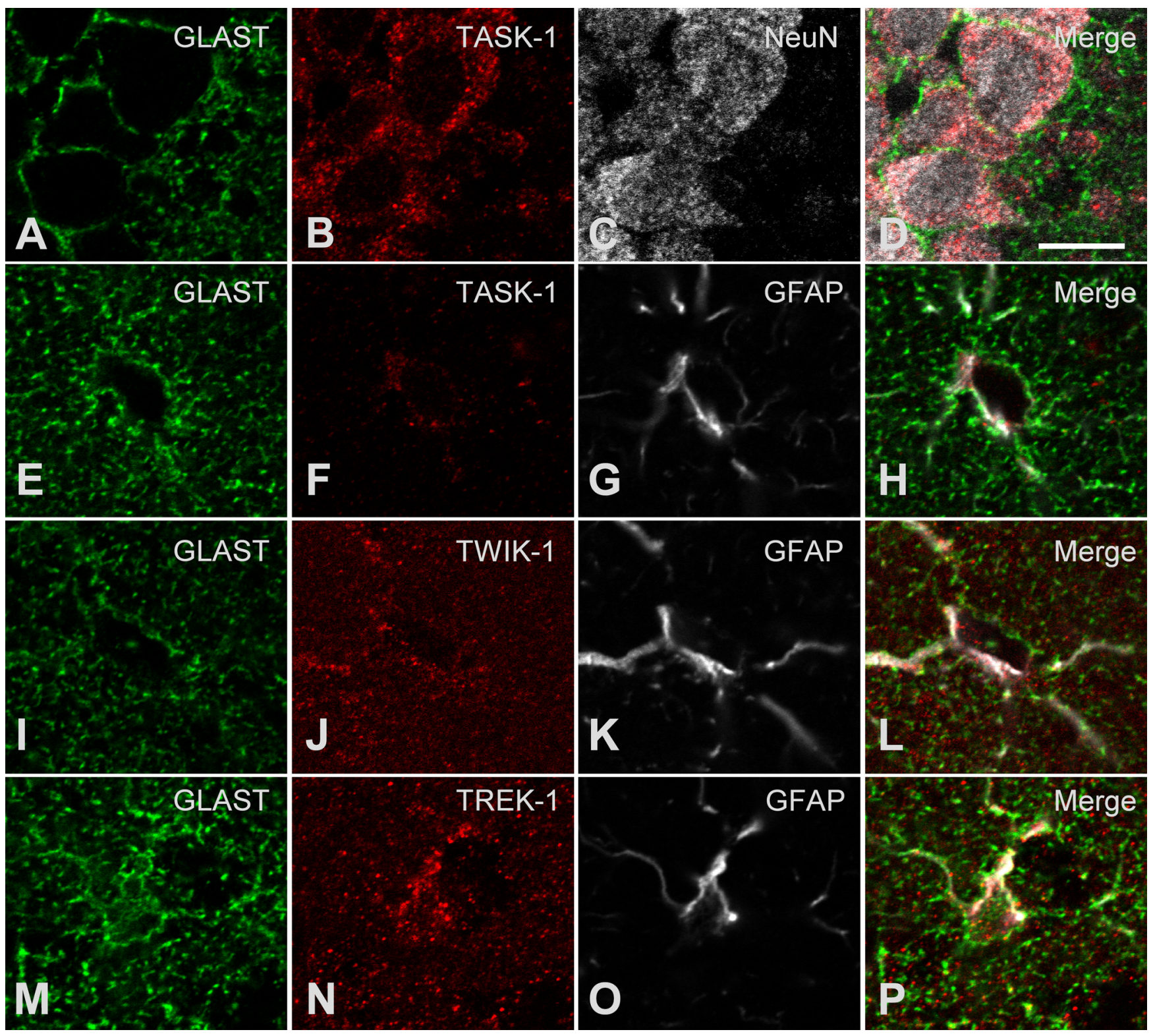

Figure 9. Immunocytochemistry of TASK-1, TWIK-1, and TREK-1 channel proteins in hippocampal sections. Coronal hippocampal sections were immun ofluorescently labeled for one of the three $K_{2 P}$ channel proteins, namely, TASK-1 $(\boldsymbol{B}, \boldsymbol{F})$, TWIK-1 $(\boldsymbol{J})$, and TREK-1 $(\boldsymbol{N}), \operatorname{GLAST},(\boldsymbol{A}, \boldsymbol{E}, \boldsymbol{I}, \boldsymbol{M})$, and NeuN $(\boldsymbol{C})$ or GFAP $(\boldsymbol{G}, \boldsymbol{K}, \boldsymbol{0})$. Shown are single confocal planes taken in the CA1 pyramidal cell layer $(\boldsymbol{A}-\boldsymbol{D})$, or the stratum radiatum $(\boldsymbol{E}-\boldsymbol{P})$. TASK-1 immunoreactivity was present in NeuN-immunoreactive pyramidal neurons $(\boldsymbol{A}-\boldsymbol{D})$ and to a lesser extent in GFAP- and GLAST-immunoreactive astrocytes $(\boldsymbol{E}-\boldsymbol{H})$. Note that the TASK-1 immunoreactivity overlaps with that for GFAP and is within the GLAST outline of the astrocyte soma (E-H). Compared with anti-TASK-1, anti-TWIK-1 and TREK-1 bound more in the neuropil, in a similar manner to anti-GLAST. These antibodies also labeled the GFAP( + ) somata (see merged images $\boldsymbol{L}$ and $\boldsymbol{P}$ ). The scale bar in $\boldsymbol{D}$ represents $10 \mu \mathrm{m}$ and applies to all images in this figure.

a strong inward rectification of whole-cell currents (Ransom and Sontheimer, 1995); and (3) the passive conductance was essentially insensitive to extracellular $\mathrm{Ba}^{2+}$, while the Kir4.1 currents should be completely inhibited by $\mathrm{Ba}^{2+}$ at micromolar concentrations (Ransom and Sontheimer, 1995). This apparently contradicted the expression of $\mathrm{K}^{+}$channel mRNAs in astrocytes that corresponded to TWIK-1 > Kir4.1 > TREK-1 (Cahoy et al., 2008). This can be rationalized on the basis that Kir4.1 are mostly present in the peripheral processes of astrocytes (Butt and Kalsi, 2006), and the currents from most of the processes can only contribute minimally to the conductance measured from the cell body because of the low membrane resistance.

The presence of other rectifying $\mathrm{K}^{+}$channels by astrocytes has also been supported by several immunocytochemical studies and cannot be excluded by whole-cell current measurements for the reason just mentioned (Verkhratsky and Steinhäuser, 2000; Olsen and Sontheimer, 2005). Also, outward rectifying $\mathrm{K}^{+}$current components were also seen in $30 \%$ excised patch recordings from astrocytic somata, where voltage clamping over a wide range of membrane potential can be achieved (Schools et al., 2006). Significant activation of rectifying $\mathrm{K}^{+}$channels requires a large shift of membrane potential, while the astrocyte membrane potential appears to be tightly controlled by $\mathrm{K}_{2 \mathrm{P}}$ channel conductance as demonstrated in this study. The membrane potential of astrocytes in vivo is also rather stable and varies within $5 \mathrm{mV}$ (Amzica and Massimini, 2002). Thus, it remains to be determined how the rectifying $\mathrm{K}^{+}$channels could function under physiological conditions. All the currently available electrophysiological tech- 
niques only allow measurement of astrocyte membrane potential from the cell body, and we have no way of knowing if the entire bushy astrocyte is isopotential.

Many questions naturally emerge from our findings. As noted, what are the locations of the different cognate proteins in terms of soma versus processes? What are the relative activities and how do they influence membrane potentials in different parts of the astrocyte? Until these questions, as well as others, are resolved the function of these $\mathrm{K}^{+}$conductances will remain unclear. Rectifying channels could be activated in pathological states, such as cerebral ischemia, where up to a $70 \mathrm{mV}$ depolarization of astrocyte membrane potential would be achieved due to the rise in $\left[\mathrm{K}^{+}\right]_{\mathrm{o}}$ which should depolarize the entire astrocyte equally (Xie et al., 2008). Studying the activity of the rectifying $\mathrm{K}^{+}$channels identified immunocytochemically and correlating these so far electrophysiologically "invisible" channels to astrocyte function are challenging issues for future research.

\section{Some functional implications of astrocytic $\mathrm{K}_{2 \mathrm{P}}$ expression}

Knowledge accumulating over the past decade has uncovered a rather dynamic behavior for $\mathrm{K}_{2 \mathrm{P}}$ channels. Namely, $\mathrm{K}_{2 \mathrm{P}}$ channels can be modulated by a variety of physiochemical stimuli and pharmacological agents (Lesage and Lazdunski, 2000; Goldstein et al., 2001; Patel and Honore, 2001; Talley et al., 2003; Kim, 2005). It would be intriguing to know whether modulation of astrocyte $\mathrm{K}_{2 \mathrm{P}}$ channels represents a yet to be determined mechanism accounting for functional astrocyte-neuron integration (Haydon and Carmignoto, 2006). To the best of our knowledge, the astrocyte is the only cell type where the $\mathrm{K}_{2 \mathrm{P}}$ conductance appears at such a high level. The current debate (Kimelberg, 2007) concerning whether astrocytes fulfill what can be best described as "support" roles in the mammalian CNS, or more active information-processing roles may, at least in part, be resolved when the identity and the functions of all the $\mathrm{K}^{+}$channels are firmly established. For example, a linear $\mathrm{K}_{2 \mathrm{P}}$-mediated conductance should be superior to any of the known $\mathrm{K}^{+}$channels for the canonical astrocyte supportive function of "K spatial buffering" (Orkand et al., 1966), with an equal efficiency for $\mathrm{K}^{+}$influx and efflux. Also, the $\mathrm{K}_{2 \mathrm{P}}$-mediated conductance would also serve to clamp the astrocyte membrane potential at a negative potential without the expenditure of energy needed to pump out $\mathrm{Na}^{+}$if there were some resting inward $\mathrm{Na}^{+}$leak. In turn the negative membrane potential, together with the large inward $\mathrm{Na}^{+}$gradient, drives uptake of electrogenic transporters, for example for glutamate and $\mathrm{pH}$ equivalents, two likely supportive functions of astrocytes (Kimelberg, 2007).

\section{Caveats}

In the present study, we have extensively compared the biophysical and pharmacological properties between astrocyte passive conductance and a cloned TWIK-1 mutant and cloned TREK-1 channels in heterologous expression systems. In addition to supportive evidence favoring the contribution of these channels to astrocytes passive conductance, the biophysical features of cloned channels also differ considerably from their likely counterparts in native astrocytes in rat hippocampal slices. For example, we've taken the advantage of a TWIK-1 mutant in this study because it produces measurable conductance. The original TWIK-1 channels actually produce little whole-cell currents, and it is yet unknown how TWIK-1 actually behaves in astrocytes and how significantly the activity of TWIK-1 channel contributes to the overall astrocyte passive conductance. The TWIK-1 mutant also exhibits a very low $\mathrm{Cs}^{+}$permeability compared with other re- ported $\mathrm{K}_{2 \mathrm{P}}$ isoforms and with TREK-1 channel and astrocyte passive conductance analyzed in this study. Bearing in mind all these discrepancies and also considering $\mathrm{K}_{2 \mathrm{P}}$ as a relatively new $\mathrm{K}^{+}$channel family with potentially more isoforms to be uncovered, more studies are needed to establish a precise relationship between astrocyte passive conductance and specific $\mathrm{K}_{2 \mathrm{P}}$ isoforms.

\section{References}

Amzica F, Massimini M (2002) Glial and neuronal interactions during slow wave and paroxysmal activities in the neocortex. Cereb Cortex 12:1101-1113.

Bergles DE, Jahr CE (1997) Synaptic activation of glutamate transporters in hippocampal astrocytes. Neuron 19:1297-1308.

Butt AM, Kalsi A (2006) Inwardly rectifying potassium channels (Kir) in central nervous system glia: a special role for Kir4.1 in glial functions. J Cell Mol Med 10:33-44.

Cahoy JD, Emery B, Kaushal A, Foo LC, Zamanian JL, Christopherson KS, Xing Y, Lubischer JL, Krieg PA, Krupenko SA, Thompson WJ, Barres BA (2008) A transcriptome database for astrocytes, neurons, and oligodendrocytes: a new resource for understanding brain development and function. J Neurosci 28:264-278.

D’Ambrosio R, Wenzel J, Schwartzkroin PA, McKhann GM 2nd, Janigro D (1998) Functional specialization and topographic segregation of hippocampal astrocytes. J Neurosci 18:4425-4438.

Djukic B, Casper KB, Philpot BD, Chin LS, McCarthy KD (2007) Conditional knock-out of Kir4.1 leads to glial membrane depolarization, inhibition of potassium and glutamate uptake, and enhanced short-term synaptic potentiation. J Neurosci 27:11354-11365.

Feliciangeli S, Bendahhou S, Sandoz G, Gounon P, Reichold M, Warth R, Lazdunski M, Barhanin J, Lesage F (2007) Does sumoylation control K2P1/TWIK1 background K+ channels? Cell 130:563-569.

Fink M, Duprat F, Lesage F, Reyes R, Romey G, Heurteaux C, Lazdunski M (1996) Cloning, functional expression and brain localization of a novel unconventional outward rectifier $\mathrm{K}^{+}$channel. EMBO J 15:6854-6862.

Goldstein SA, Wang KW, Ilan N, Pausch MH (1998) Sequence and function of the two P domain potassium channels: implications of an emerging superfamily. J Mol Med 76:13-20.

Goldstein SA, Bockenhauer D, O'Kelly I, Zilberberg N (2001) Potassium leak channels and the KCNK family of two-P-domain subunits. Nat Rev Neurosci 2:175-184.

Haydon PG, Carmignoto G (2006) Astrocyte control of synaptic transmission and neurovascular coupling. Physiol Rev 86:1009-1031.

Hille B (2001) Ion channels of excitable cells. Sunderland, MA: Sinauer.

Jabs R, Paterson IA, Walz W (1997) Qualitative analysis of membrane currents in glial cells from normal and gliotic tissue in situ: down-regulation of $\mathrm{Na}^{+}$current and lack of P2 purinergic responses. Neuroscience 81:847-860.

Kang J, Jiang L, Goldman SA, Nedergaard M (1998) Astrocyte-mediated potentiation of inhibitory synaptic transmission. Nat Neurosci 1:683-692.

Kim D (2005) Physiology and pharmacology of two-pore domain potassium channels. Curr Pharm Des 11:2717-2736.

Kimelberg HK (2007) Supportive or information-processing functions of the mature protoplasmic astrocyte in the mammalian CNS? A critical appraisal. Neuron Glia Biol 3:181-189.

Kindler CH, Yost CS, Gray AT (1999) Local anesthetic inhibition of baseline potassium channels with two pore domains in tandem. Anesthesiology 90:1092-1102.

Kindler CH, Pietruck C, Yost CS, Sampson ER, Gray AT (2000) Localization of the tandem pore domain $\mathrm{K}^{+}$channel TASK-1 in the rat central nervous system. Brain Res Mol Brain Res 80:99-108.

Lesage F, Lazdunski M (2000) Molecular and functional properties of twopore-domain potassium channels. Am J Physiol Renal Physiol 279:F793-801.

Lesage F, Guillemare E, Fink M, Duprat F, Lazdunski M, Romey G, Barhanin J (1996) TWIK-1, a ubiquitous human weakly inward rectifying $\mathrm{K}^{+}$ channel with a novel structure. EMBO J 15:1004-1011.

Lesage F, Lauritzen I, Duprat F, Reyes R, Fink M, Heurteaux C, Lazdunski M (1997) The structure, function and distribution of the mouse TWIK-1 $\mathrm{K}^{+}$channel. FEBS Lett 402:28-32.

Lopes CM, Gallagher PG, Buck ME, Butler MH, Goldstein SA (2000) Pro- 
ton block and voltage gating are potassium-dependent in the cardiac leak channel Kcnk3. J Biol Chem 275:16969-16978.

Lotshaw DP (2007) Biophysical, pharmacological, and functional characteristics of cloned and native mammalian two-pore domain $\mathrm{K}^{+}$channels. Cell Biochem Biophys 47:209-256.

Meadows HJ, Benham CD, Cairns W, Gloger I, Jennings C, Medhurst AD, Murdock P, Chapman CG (2000) Cloning, localisation and functional expression of the human orthologue of the TREK-1 potassium channel. Pflugers Arch 439:714-722.

Niemeyer MI, Cid LP, Barros LF, Sepúlveda FV (2001) Modulation of the two-pore domain acid-sensitive $\mathrm{K}^{+}$channel TASK-2 (KCNK5) by changes in cell volume. J Biol Chem 276:43166-43174.

Olsen M, Sontheimer H (2005) Voltage-gated ion channels in glia cells. In: Neuroglia, Ed 2 (Kettenmann H, Ranson BR, eds), pp 112-130. Oxford: Oxford UP.

Orkand RK, Nicholls JG, Kuffler SW (1966) Effect of nerve impulses on the membrane potential of glial cells in the central nervous system of amphibia. J Neurophysiol 29:788-806.

Patel AJ, Honoré E (2001) Properties and modulation of mammalian 2P domain $\mathrm{K}^{+}$channels. Trends Neurosci 24:339-346.

Patel AJ, Honoré E, Maingret F, Lesage F, Fink M, Duprat F, Lazdunski M (1998) A mammalian two pore domain mechano-gated S-like K+ channel. EMBO J 17:4283-4290.

Patel AJ, Honoré E, Lesage F, Fink M, Romey G, Lazdunski M (1999) Inhalational anesthetics activate two-pore-domain background $\mathrm{K}+$ channels. Nat Neurosci 2:422-426.

Pountney DJ, Gulkarov I, Vega-Saenz de Miera E, Holmes D, Saganich M, Rudy B, Artman M, Coetzee WA (1999) Identification and cloning of TWIK-originated similarity sequence (TOSS): a novel human 2-pore $\mathrm{K}^{+}$ channel principal subunit. FEBS Lett 450:191-196.

Rajan S, Plant LD, Rabin ML, Butler MH, Goldstein SA (2005) Sumoylation silences the plasma membrane leak $\mathrm{K}^{+}$channel K2P1. Cell 121:37-47.

Ransom CB, Sontheimer H (1995) Biophysical and pharmacological characterization of inwardly rectifying $\mathrm{K}+$ currents in rat spinal cord astrocytes. J Neurophysiol 73:333-346.

Rusznák Z, Pocsai K, Kovács I, Pór A, Pál B, Bíró T, Szücs G (2004) Differential distribution of TASK-1, TASK-2 and TASK-3 immunoreactivities in the rat and human cerebellum. Cell Mol Life Sci 61:1532-1542.

Schools GP, Zhou M, Kimelberg HK (2003) Electrophysiological "com- plex" glial cells freshly isolated from the hippocampus are immunopositive for the chondroitin sulfate proteoglycan NG2. J Neurosci Res 73:765-777.

Schools GP, Zhou M, Kimelberg HK (2006) Development of gap junctions in hippocampal astrocytes: evidence that whole cell electrophysiological phenotype is an intrinsic property of the individual cell. J Neurophysiol 96:1383-1392.

Steinhäuser C, Berger T, Frotscher M, Kettenmann H (1992) Heterogeneity in the membrane current pattern of identified glial cells in the hippocampal slice. Eur J Neurosci 4:472-484.

Talley EM, Sirois JE, Lei Q, Bayliss DA (2003) Two-pore-domain (KCNK) potassium channels: dynamic roles in neuronal function. Neuroscientist 9:46-56.

Taverna S, Tkatch T, Metz AE, Martina M (2005) Differential expression of TASK channels between horizontal interneurons and pyramidal cells of rat hippocampus. J Neurosci 25:9162-9170.

Torborg CL, Berg AP, Jeffries BW, Bayliss DA, McBain CJ (2006) TASK-like conductances are present within hippocampal CA1 stratum oriens interneuron subpopulations. J Neurosci 26:7362-7367.

Verkhratsky A, Steinhäuser C (2000) Ion channels in glial cells. Brain Res Brain Res Rev 32:380-412.

Wallraff A, Köhling R, Heinemann U, Theis M, Willecke K, Steinhäuser C (2006) The impact of astrocytic gap junctional coupling on potassium buffering in the hippocampus. J Neurosci 26:5438-5447.

Xie M, Lynch DT, Schools GP, Feustel PJ, Kimelberg HK, Zhou M (2007) Sodium channel currents in rat hippocampal NG2 glia: characterization and contribution to resting membrane potential. Neuroscience 150:853-862.

Xie M, Wang W, Kimelberg HK, Zhou M (2008) Oxygen and glucose deprivation-induced changes in astrocyte membrane potential and their underlying mechanisms in acute rat hippocampal slices. J Cereb Blood Flow Metab 28:456-467.

Zhou M, Kimelberg HK (2000) Freshly isolated astrocytes from rat hippocampus show two distinct current patterns and different $\left[\mathrm{K}^{+}\right](\mathrm{o})$ uptake capabilities. J Neurophysiol 84:2746-2757.

Zhou M, Schools GP, Kimelberg HK (2006) Development of GLAST(+) astrocytes and $\mathrm{NG2}(+)$ glia in rat hippocampus CA1: mature astrocytes are electrophysiologically passive. J Neurophysiol 95:134-143. 